\title{
Spectroscopic and theoretical approaches for studying radical reactions in class I ribonucleotide reductase
}

\section{Marina Bennati', Friedhelm Lendzian ${ }^{2, *}$, Michael Schmittel ${ }^{3}$ and Hendrik Zipse ${ }^{4}$}

${ }^{1}$ Institut für Physikalische und Theoretische Chemie und BMRZ, J.W. Goethe-Universität Frankfurt, Marie-CurieStr. 11, D-60439 Frankfurt am Main, Germany

${ }^{2}$ Technische Universität Berlin, Institut für Chemie, Max-Volmer-Labor, Straße des 17. Juni 135, D-10623 Berlin, Germany

${ }^{3}$ Universität Siegen, Organische Chemie I, Fachbereich 8, Adolf-Reichwein Str., D-57068 Siegen, Germany

${ }^{4}$ Department Chemie und Biochemie, LudwigMaximilians-Universität München, Butenandtstrasse 5-13, D-81377 München, Germany

${ }^{*}$ Corresponding author

\begin{abstract}
Ribonucleotide reductases (RNRs) catalyze the production of deoxyribonucleotides, which are essential for DNA synthesis and repair in all organisms. The three currently known classes of RNRs are postulated to utilize a similar mechanism for ribonucleotide reduction via a transient thiyl radical, but they differ in the way this radical is generated. Class I RNR, found in all eukaryotic organisms and in some eubacteria and viruses, employs a diferric iron center and a stable tyrosyl radical in a second protein subunit, $R 2$, to drive thiyl radical generation near the substrate binding site in subunit R1. From extensive experimental and theoretical research during the last decades, a general mechanistic model for class I RNR has emerged, showing three major mechanistic steps: generation of the tyrosyl radical by the diiron center in subunit $\mathrm{R} 2$, radical transfer to generate the proposed thiyl radical near the substrate bound in subunit $\mathrm{R} 1$, and finally catalytic reduction of the bound ribonucleotide. Amino acid- or substrate-derived radicals are involved in all three major reactions. This article summarizes the present mechanistic picture of class I RNR and highlights experimental and theoretical approaches that have contributed to our current understanding of this important class of radical enzymes.
\end{abstract}

Keywords: amino acid-based radicals; catalytic mechanism; density functional theory; high-field EPR/ ENDOR; hydrogen abstraction; ribonucleotide reductase.

\section{Introduction}

The enzymatic reduction of ribonucleotides to deoxyribonucleotides as catalyzed by the ribonucleotide reduc- tase (RNR) (Sjöberg, 1997; Eklund et al., 2001; Stubbe et al., 2003; Kolberg et al., 2004) has emerged over the last two decades as a spectacular showcase of the unique potential of biological radical chemistry. Several mechanistically unique and still controversial features characterize the mode of action of RNR, in particular the generation of a transient cysteinyl radical in the active site by a long-range proton-coupled electron transfer and the elimination of the 2'-hydroxyl of the ribonucleotide triggered by the cysteinyl radical (Figure 1).

Three main classes of ribonucleotide reductases have been described, that are all proposed to be initiated by a transient thiyl radical situated near the substrate (Reichard, 1993; Sjöberg, 1997; Stubbe and van der Donk, 1998; Kolberg et al., 2004) and that are best classified according to the radical generator driving the catalytic reaction. Class II enzymes use cobalamin as the cofactor for generation of the functionally essential thiyl radical that remains strongly coupled to the cobalt ion (Licht et al., 1996). Class III enzymes are strictly anaerobic and form a stable glycyl radical with the help of an iron-sulfur protein and S-adenosyl methionine (Eklund et al., 2001; Fontecave et al., 2002). This article focuses on class I $\mathrm{RNR}$, which is found in practically all eukaryotic organisms, from yeast and algae to plants and mammals, and equally in some eubacteria and viruses. The best understood class I RNR from $E$. coli consists of two homodimeric proteins, R1 and R2 (see Figure 2; Nordlund et al., 1990; Uhlin and Eklund, 1994; Eklund et al., 2001; Kolberg et al., 2004). While the substrate turnover reaction is performed in $\mathrm{R} 1$, the role of protein $\mathrm{R} 2$ is to harbor in the active state a tyrosyl radical, $\mathrm{Y} 122^{\circ}(E$. coli numbering), located close to a diferric iron center. X-Ray structures have been determined separately for R2 and for R1 with substrate and one effector bound (Figure 2; Nordlund et al., 1990; Uhlin and Eklund, 1994).

Three steps have been mechanistically identified in the reactions of class I RNR that indispensably depend on the presence and action of radicals: (i) the activation reaction of the diferrous center with molecular oxygen, generating the tyrosyl radical in subunit $\mathrm{R} 2$, which is essential for catalytic activity (Tong et al., 1996; Kolberg et al., 2004); (ii) the radical transfer reaction from the tyrosyl radical $\mathrm{Y} 122^{\circ}$ in protein $\mathrm{R} 2$ to generate the putative thiyl radical at $\mathrm{C} 439$ in protein $\mathrm{R} 1$ (Sjöberg, 1997; Siegbahn et al., 1998; Stubbe et al., 2003); and (iii) catalytic reduction of the bound ribonucleotide to the corresponding deoxyribonucleotide initiated by the thiyl radical C439. For step (iii), several intermediate radical states have been proposed based on extensive experimental and theoretical studies involving RNR mutants and mechanism-based inhibitors (van der Donk et al., 1996; 

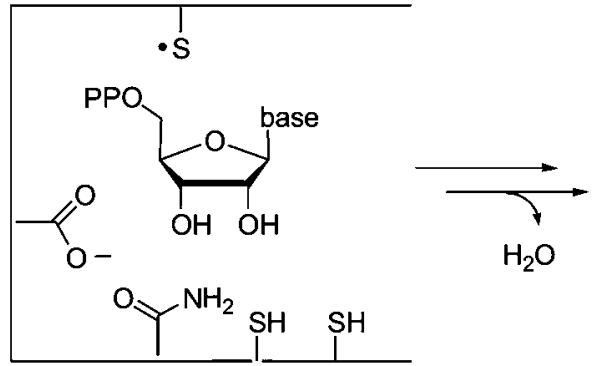

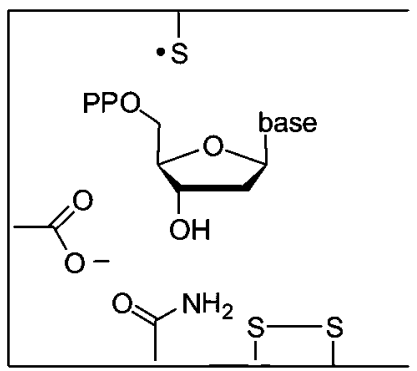

Figure 1 The black box reaction in the active site of $R 1$ of RNR.

Sjöberg, 1997; Persson et al., 1998; Siegbahn, 1998; Lawrence et al., 1999; Stubbe et al., 2003; Zipse, 2003; Kolberg et al., 2004).

In this short review we outline experimental and theoretical approaches that have been used for investigation of the reaction pathways and intermediates of the three radical reactions, and which have significantly contributed to our current understanding of the reaction mechanism. On the experimental side, these are recent high-field electron paramagnetic resonance (EPR), electron nuclear double resonance (ENDOR) and electronelectron double resonance (ELDOR) experiments, while on the theoretical side much has been learned from studies based on density functional theory (DFT).

\section{Radical generation reaction in protein $\mathbf{R} 2$}

\section{Functional transient diiron states and radicals in the activation reaction of class I RNR}

The tyrosyl radical is generated in an activation reaction either from the diferrous R2 with molecular oxygen, or by reaction of the apo-protein with Fe"l-solution and molecular oxygen (reconstitution) (Atkin et al., 1973; Tong et al., 1996). In the latter case the overall reaction proceeds according to Eq. (1) (Bollinger et al., 1994a):

$$
\begin{aligned}
& \text { Apo-R2-Y122+2Fe }{ }^{\prime \prime}+\mathrm{O}_{2}+\mathrm{H}^{+}+\mathrm{e}^{-} \\
& \rightarrow \mathrm{R} 2-\mathrm{Y} 122^{\circ}+\mathrm{Fe}^{\prime \prime \prime}-\mathrm{O}-\mathrm{Fe}^{\text {III }}+\mathrm{H}_{2} \mathrm{O}
\end{aligned}
$$

The mechanism of this activation reaction has been investigated in detail by several groups. The reductive cleavage of the oxygen molecule requires four electrons, three of which come from the two Fell ions and the tyrosine $\mathrm{Y} 122$; the fourth electron has to come from another source (Bollinger et al., 1991, 1994a,b; Nordlund and Eklund, 1993). In an early stopped-flow absorption spectroscopy and freeze-quench EPR study (Bollinger et al., 1991), a peroxodiferric complex followed by an iron-coupled radical, showing pronounced broadening upon ${ }^{57} \mathrm{Fe}$ substitution, were proposed as intermediates in this reaction. The peroxodiiron intermediate was later confirmed by resonance Raman (RR) spectroscopy (Moenne-Loccoz et al., 1998) and can be accumulated in protein variants, where electron flow from W48 is prohibited (Baldwin et al., 2003). It was shown by EPR and Mössbauer studies that subsequent electron transfer to the $\left(\mathrm{Fe}_{2} \mathrm{O}_{2}\right)^{4+}$ peroxodiiron center from W48, which is near the protein surface, leads to the cation radical $\mathrm{W}_{4} 8^{+*}$, con- comitant with a high-valent paramagnetic diiron state, the so-called intermediate ' $X$ '. The simultaneous existence of the radical and the intermediate ' $X$ ', also having spin $S=1 / 2$, was evidenced by magnetic coupling in the EPR spectra (Baldwin et al., 2000). In variant W48F, a coupled ' $X$ '-Y122' EPR signal was observed (Krebs et al., 2000). In the presence of an external electron source, the tryptophan cation radical $\mathrm{W} 48^{+\bullet}$ is rapidly reduced (Baldwin et al., 2000), whereas ' $X$ ' has a lifetime of $\sim 1 \mathrm{~s}$ in E. coli RNR. A similar overall reaction scheme was found for the activation reaction of mouse RNR (Yun et al., 2002). ' $X$ ' has been investigated extensively using a variety of spectroscopic methods. Early investigations using Mössbauer spectroscopy assigned ' $X$ ' as a strongly coupled diferric iron-radical center (Bollinger et al., 1994b; Ravi et al., 1994). In a later, combined 35-GHz ENDOR and Mössbauer study, it was shown that ' $X$ ' is better described as a Fe"'Fe $e^{\mathrm{IV}}$ state (Sturgeon et al., 1996). Dinuclear Fe ${ }^{\text {IIIFe }} \mathrm{Fe}^{\mathrm{VV}}$ model complexes have been prepared and characterized (Dong and Que, 1995). Extended X-ray absorption fine structure (EXAFS) studies of ' $X$ ' showed a short iron-iron distance (2.5 $\AA$ ) (Riggs-Gelasco et al., 1998), from which the presence of two $\mu$-oxo bridges was suggested. A structural model with two $\mu$-oxo bridges and one carboxylate bridge was proposed based on X-ray structure data of R2 having azide bound to the diiron center (Andersson et al., 1999). Theoretical studies by different groups agree well with this general coordination; however, the protonation state of the bridging oxygens and one terminal water (or $\left.\mathrm{OH}^{-}\right)$is under debate (Siegbahn, 1999; Han et al., 2004). Knowledge of the detailed structure of this high-valent diiron intermediate is important, since it is crucial for generating the tyrosyl radical. In the structural diiron enzyme homologue methane monooxygenase (MMO) with a different diiron ligation, reaction with $\mathrm{O}_{2}$ leads to an intermediate $\mathrm{Fe}^{\mathrm{IV}} \mathrm{Fe}^{\mathrm{Iv}}$ species and no tyrosyl radical is formed; instead, hydrocarbon substrates are oxidized (Baik et al., 2003). In

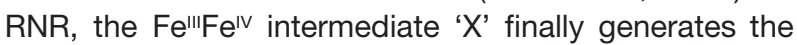
tyrosyl radical $\mathrm{Y} 122^{\circ}$, which is approximately $5 \AA$ from Fe1, by abstraction of one proton and one electron, thereby turning the diiron cluster into the antiferromagnetically coupled diferric state (Bollinger et al., 1994a,b). It has been shown by Raman spectroscopy using ${ }^{18} \mathrm{O}$ labeled $\mathrm{O}_{2}$ that the oxygen molecule is indeed split and one of its oxygen atoms forms a $\mu$-oxo-bridge between the two irons in the final active form (Ling et al., 1994), whereas the other oxygen is found in a terminal water ligand. The observation of a transient tryptophan cation radical at position W48 (Bollinger et al., 1994b; Baldwin 


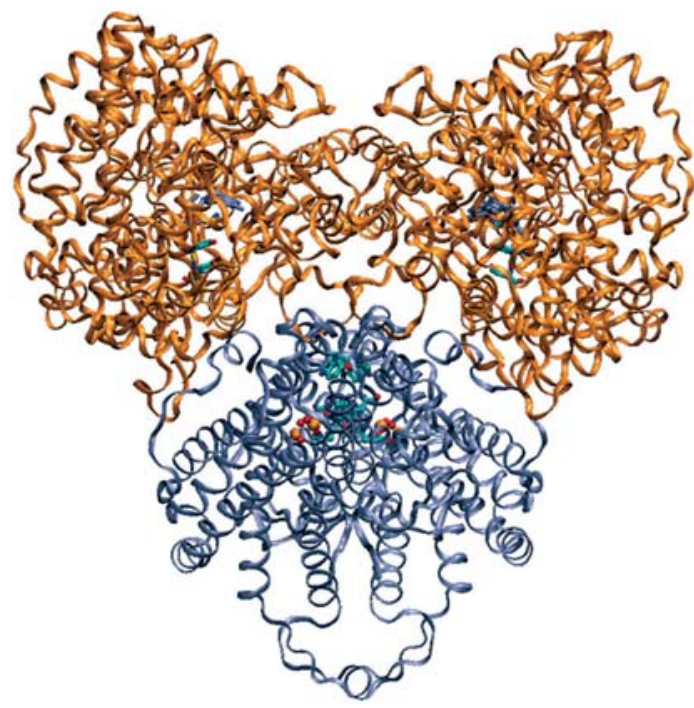

Figure 2 Structural model for the R2-R1 holoenzyme complex of RNR from E. coli (modified from Uhlin and Eklund, 1994; Sjöberg, 1997).

Structures for the homodimeric subunits R2 (blue, diferric form; Nordlund et al., 1990) and R1 (orange; Uhlin and Eklund, 1994) have been solved separately. The two irons (yellow) with bridging oxygen and terminal water ligands (red), and selected amino acids from the proposed electron/proton transfer pathway, Y122, H118, W48 (cyan) in R2, and Y731, Y730 (cyan) and the bound GDP (blue) in R1 are indicated (see text).

et al., 2000; Krebs et al., 2000) is of particular interest. It suggests that for the radical generation reaction within $\mathrm{R} 2$, the same electron transfer pathway is used as for the catalytic radical transfer from $\mathrm{Y} 122^{\circ}$ in $\mathrm{R} 2$ to $\mathrm{C} 439$ in $\mathrm{R} 1$, where involvement of W48 was also proposed (Uhlin and Eklund, 1994; Ekberg et al., 1996; Rova et al., 1999).

\section{Structure and protein interactions of the tyrosyl radical in class I RNR}

Since its early discovery (Ehrenberg and Reichard, 1972) the tyrosyl radical Y122 (Figure 3), in class I RNR of $E$. coli has been extensively investigated by EPR techniques. Its hyperfine (hf) structure has been characterized in detail by several groups, using conventional and highfield EPR and ENDOR techniques (Bennati et al., 1999).

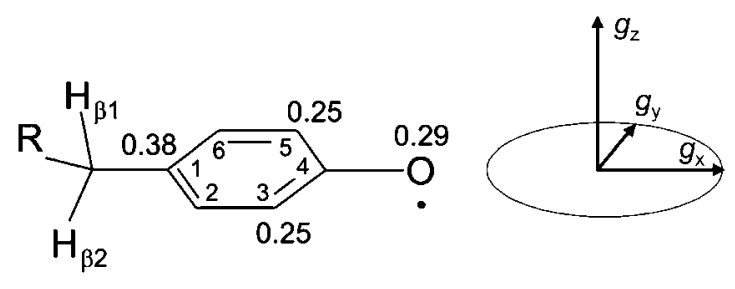

Figure 3 Molecular structure and numbering for the tyrosyl radical.

The outer numbers denote the major $\pi$-spin densities deduced from EPR and ENDOR experiments (see text). Together with small negative spin densities at positions 2 and $6(-0.08)$ and at position C4 $(-0.05)$ and a small positive spin density at $\mathrm{C}$ (methylene) $(+0.03)$, these numbers add up to a total spin density of 1 (Hoganson et al., 1996). Molecular and $g$-tensor axes systems for the tyrosyl radical are collinear (Mezzetti et al., 1999).
For reviews of these studies see Bennati et al. (2001) and Lendzian (2005). Similar ENDOR studies were performed on the radical $\mathrm{Y} 177^{\circ}$ in mouse RNR (van Dam et al., 1998) and the tyrosyl radical in yeast RNR (Bar et al., 2001).

From these studies it was concluded that the overall spin density distribution of the tyrosyl radicals shown in Figure 3 was very similar in these class I RNRs. The tyrosyl radical in a second RNR, termed class $\mathrm{lb}$, which was found as the active aerobic enzyme in some bacteria, e.g., Mycobacterium tuberculosis, showed significantly different hf tensors of the $\beta$-protons of the tyrosyl side chain compared with the class la enzymes present in E. coli and mouse (Liu et al., 2000). Class Ib RNR has a very similar overall structure for $\mathrm{R} 2$ compared with class la from E. coli (Figure 1) or mouse, except for a greater distance between the tyrosyl radical and the diiron site. However, in contrast to class la, class lb lacks overall allosteric activity regulation (Eklund et al., 2001). The difference in hf tensors of the $\beta$-protons between class la and class $\mathrm{lb}$ was attributed to geometrically different side-chain orientations (see Figure 3; Liu et al., 2000; Eklund et al., 2001; Lendzian, 2005) largely determined by protein constraints. Indeed, theoretical studies indicated that the side chain orientations of the tyrosyl radicals $\mathrm{Y}_{122^{\circ}}$ in E. coli RNR and of the tyrosyl radical in class Ib RNR correspond to two energetic minima (Himo et al., 1997).

The electronic $g$-tensor has been determined with high accuracy using high-field EPR for the tyrosyl radicals in RNR from a variety of organisms (Gerfen et al., 1993; Bennati et al., 2001; Lendzian, 2005). Interestingly, the $g_{x}$ component of tyrosyl radicals in class I RNR has not the same value for all organisms. Two groups of tyrosyl radicals were found, one group with a $g_{x}$ value of approximately 2.0076 (mouse, yeast, and virus HSV1 RNR) and another group with $g_{\mathrm{x}}$ values between 2.0089 and 2.0092 (E. coli, M. tuberculosis, S. thyphimurium RNR) (Schmidt et al., 1996; Bar et al., 2001; Lendzian, 2005). Using experimental and theoretical studies, this difference was traced back to polar interactions, in particular those that involve hydrogen bonding to the oxygen attached to the tyrosine ring, as in mouse and yeast RNR (Schmidt et al., 1996; Engström et al., 2000; Un et al., 2001). The presence of such a hydrogen bond was unambiguously proven for mouse and yeast RNR by ${ }^{2} \mathrm{H}$-ENDOR on samples exchanged in ${ }^{2} \mathrm{H}_{2} \mathrm{O}$ (van van Dam et al., 1998; Bar et al., 2001). Interestingly, the tyrosyl radical in class lb Mycobacterium tuberculosis was found to exhibit a heterogeneity showing stretched $g_{x}$ values between 2.0092 and 2.0080 and it was speculated that the enzyme may be activated by connecting the radical to the chain of hydrogen bonds (Liu et al., 2000).

\section{Reorientation induced by tyrosyl radical formation (94-GHz single-crystal EPR)}

Crystal structures of $E$. coli R2 are available for both the reduced diferrous (Fe"Fe"l-Y122-OH) form and the diferric, so-called 'met' form lacking the radical (Fe'"'Fe'II$\mathrm{Y} 122-\mathrm{OH})$ (Eklund et al., 2001), but not for the active radical form of $R 2$, because the tyrosyl radical $Y 122^{\circ}$ is too short-lived to survive crystallization of the protein. The question of the amount of displacement (reorienta- 


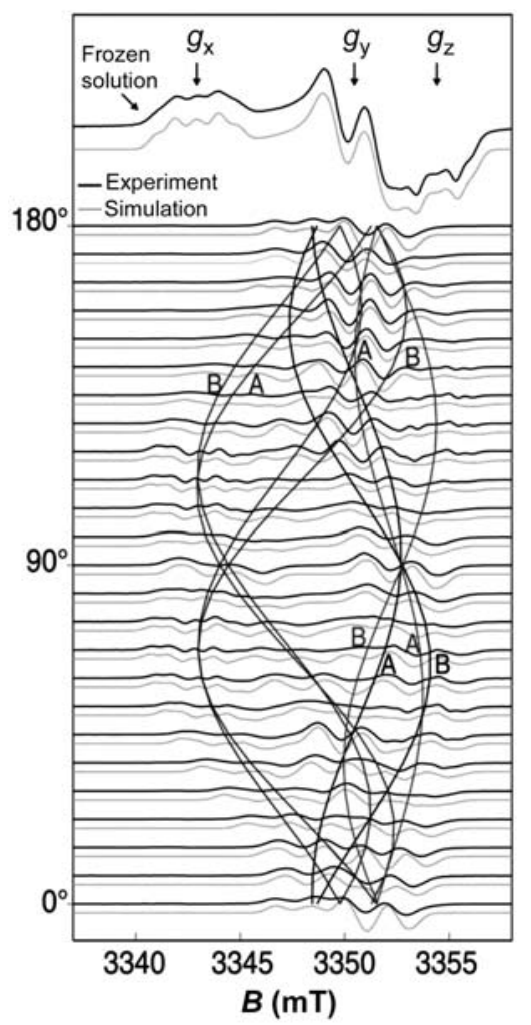

Figure 4 Angular-dependent 94-GHz EPR spectra of the tyrosyl radical $\mathrm{Y}^{\circ} 2^{\circ}$ in R2 single crystals of $E$. coli RNR (Högbom et al., 2003).

Effective $g$-values (cosine patterns) for each crystallographic site in the protein chain $A$ and $B$ are indicated.

tion) of the tyrosine $\mathrm{Y} 122$ upon radical formation has been investigated in a recent combined high-field EPR and high-resolution (1.4 ̊) X-ray single-crystal study (Högbom et al., 2003). Thus, the orientation of the $g$-tensor axes of the radical $\mathrm{Y} 122^{\circ}$ in the crystal was determined with high precision by single-crystal high-field EPR. The $g$-tensor axes of the tyrosyl radical were known to be collinear with its molecular axes (Figure 3) from a previous study on irradiated tyrosine crystals (Mezzetti et al., 1999). The radical $Y 122^{\circ}$ was generated in single crystals of R2 by reaction of met-R2 (Fe'I'Fe'l'-Y122-OH) with $\mathrm{H}_{2} \mathrm{O}_{2}$, a method that was previously used for $\mathrm{R} 2$ protein solutions to generate the tyrosyl radical and restore catalytic activity (Sahlin et al., 1990). The radical yields obtained in the crystals of approximately $10 \%$ were too low for determining the X-ray structure for the radical state, but sufficient to obtain well-resolved single-crystal EPR spectra with good signal/noise ratio. Angulardependent $94-\mathrm{GHz}$ high-field EPR spectra were recorded and a full $180^{\circ}$ rotation pattern of the spectra is shown in Figure 4 (dark traces). The data were analyzed by simultaneous simulation of all spectra (light gray traces) for all eight sites in the crystal and for all orientations using the known crystal symmetry (orthorhombic space group $P 2{ }_{1} 2_{1} 2_{1}$ ) and the symmetry axis relating chains $A$ and $B$ of the protein R2 homodimer (Högbom et al., 2003).

Analysis of the spectra showed that $60-70 \%$ of the relative radical yield was located in protein chain $A$ and only $30-40 \%$ in chain $\mathrm{B}$. Interestingly, the maximum radi- cal yield determined from reconstituted frozen solutions of R2 was also reported to have a non-stoichiometric value of ca. 1.2 per protein dimer (Miller et al., 1999). The radical $\mathrm{Y} 122^{\circ}$ was found to be rotated with respect to the reduced tyrosine, $\mathrm{Y} 122-\mathrm{OH}$, leading to angles of $10^{\circ}, 8^{\circ}$, and $5^{\circ}$ (errors $\pm 1^{\circ}$ ) between their respective molecular $x-, y-$, and $z$-axes (see Figure 3 for axes). This radical orientation was achieved in the structural model by rotations of $11^{\circ}$ about the $\mathrm{C}_{\alpha}-\mathrm{C}_{\beta}$ and $-3^{\circ}$ about the $\mathrm{C}_{\beta}-\mathrm{C}_{1}$ bonds, as shown in Figure 5. The main effect of this reorientation was displacement of the tyrosine oxygen, away from the diiron site. In the met form of R2, the oxygen of the reduced tyrosine has a distance of approximately $3.2 \AA$ from one of the oxygens of D84, probably forming a weak $\mathrm{H}$-bond. This distance is increased to over $4 \AA$ in the radical form, which is too large for hydrogen bonding to D84 (Högbom et al., 2003). The observed conformational change induced by radical formation coupling or uncoupling Y122 from the metal site and from the hydrogen bond network (Figure 5) - probably contributes to the remarkable stability of the radical and may assist in controlling reversible protonation/deprotonation of the tyrosyl, proposed for the radical transfer reaction, generating the thiyl radical in subunit R1 (Siegbahn, 1998).

\section{Radicals generated in protein $\mathbf{R} 2$ variants with replaced tyrosine}

Several mutants have been investigated in which the active tyrosyl radical has been replaced by other amino acids to investigate the mechanism and intermediates of the iron/oxygen reconstitution reaction in $\mathrm{R} 2$ in more detail, and to explore which amino acid radicals other than tyrosine may be generated and may possibly be functionally competent.

\section{Tryptophan neutral radicals}

When tyrosine $\mathrm{Y} 122$ in $\mathrm{R} 2$ of $E$. coli was replaced with phenylalanine (mutant Y122F), two different tryptophan radicals were observed as reaction intermediates of the iron/oxygen reconstitution reaction. They have been

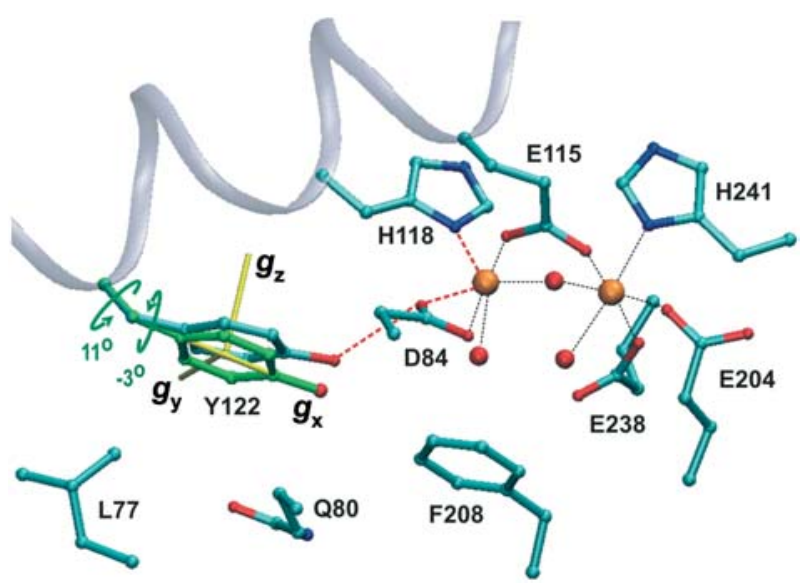

Figure 5 Reorientation of reduced tyrosine Y122 (cyan) as compared with the radical form (green, $g$-tensor axes yellow), showing a disruption of the radical from the network of hydrogen-bonded amino acids in R2. 
identified by EPR and ENDOR spectroscopy using indol$\mathrm{d}_{5}$ tryptophan labeling and were characterized as neutral radicals, deprotonated at the indole nitrogen. Based on the resolved hf tensors of the side chain protons, the side chain orientation for both tryptophan radicals was obtained. This allowed site-specific assignment of one radical, observed in freeze-quenched samples, to residue $\mathrm{W} 111$, and the second radical, observed in stopped-flow experiments, to W107, based on comparison with the Xray structure (Lendzian et al., 1996). A similar neutral tryptophan radical was observed and characterized by ENDOR in mutant $\mathrm{Y} 177 \mathrm{~W}$ of mouse RNR, for which it was assigned to residue W177 (Pötsch et al., 1999). High-field EPR (94 GHz or higher frequency) proved to be very useful for radical identification, in particular for discriminating tryptophan and tyrosyl radicals based on the much greater $g$-anisotropy for the latter case (Bleifuß et al., 2001).

The tryptophan neutral radicals observed at residues $\mathrm{W} 111$ and $\mathrm{W} 107$ in E. coli variant $\mathrm{Y} 122 \mathrm{~F}$ show the presence of different electron pathways compared with the wild-type $\mathrm{R} 2$ and indicate that these tryptophan neutral radicals in $\mathrm{Y} 122 \mathrm{~F}$ are probably more stable than the cation radical $\mathrm{W}_{48^{+\cdot}}$ (see above). Standard activity assays performed with the $E$. coli and mouse mutants (Y122F, Y177W) exhibiting tryptophan radicals showed no catalytic activity (Pötsch et al., 1999). Activity might have been expected for mutant $\mathrm{Y} 177 \mathrm{~W}$ of mouse RNR, in which the radical $\mathrm{W} 177^{\circ}$ was at the same site as the tyrosyl radical $\mathrm{Y} 177^{\circ}$ in the wild type, but was probably obscured by the short lifetime of this radical of only $30 \mathrm{~s}$ (Pötsch et al., 1999).

\section{Radical-iron centers in variants with hydroxylated F208 in R2 of E. coli}

Several mutants of $E$. coli RNR in which amino acids near the diiron site of R2 were replaced (Y122F/E238A, F208Y, and W48F/D84E) showed self-hydroxylation reaction of the aromatic amino-acid residue F208 (Figure 5) next to the diiron site (Logan et al., 1998; Baldwin et al., 2001). A new class of strongly coupled radical-iron centers has been observed in some of these mutants. In F208Y the iron/oxygen reconstitution reaction was reported to show branching, with one branch leading to an EPR singlet signal, which was attributed to an oxo-ferryl species, possibly in equilibrium with a radical on Y208 (Liu et al., 1998). A similar EPR signal was also observed in mutant $\mathrm{Y} 122 \mathrm{H}$.

Recently, mutants $\mathrm{Y} 122 \mathrm{H}$ (Kolberg et al., 2005) and F208Y (Galander et al., unpublished results) of R2 of $E$. coli RNR have been investigated in comparison with $F^{\prime I I I F} \mathrm{I}^{\mathrm{IV}}$ intermediate ' $\mathrm{X}$ ' in the diiron oxygen reconstitution reaction. Samples from both mutants grown on ${ }^{57} \mathrm{Fe}-$ medium showed a significant isotope effect in the EPR spectra of their paramagnetic species, similar to the Fe'IIFelv intermediate ' $X$ ' (Galander et al., unpublished results; Kolberg et al., 2005). Figure 6 compares the ENDOR spectra of ${ }^{57} \mathrm{Fe}$-enriched samples from both mutants and intermediate ' $\mathrm{X}$ ', showing ${ }^{14} \mathrm{~N}-,{ }^{1} \mathrm{H}-$, and ${ }^{57} \mathrm{Fe}-\mathrm{ENDOR}$ lines. Two groups of ${ }^{57} \mathrm{Fe}-\mathrm{ENDOR}$ lines were observed in the spectrum of $\mathrm{Y} 122 \mathrm{H}$ at 35 and $24 \mathrm{MHz}$, clearly indicating large spin densities on both irons. The

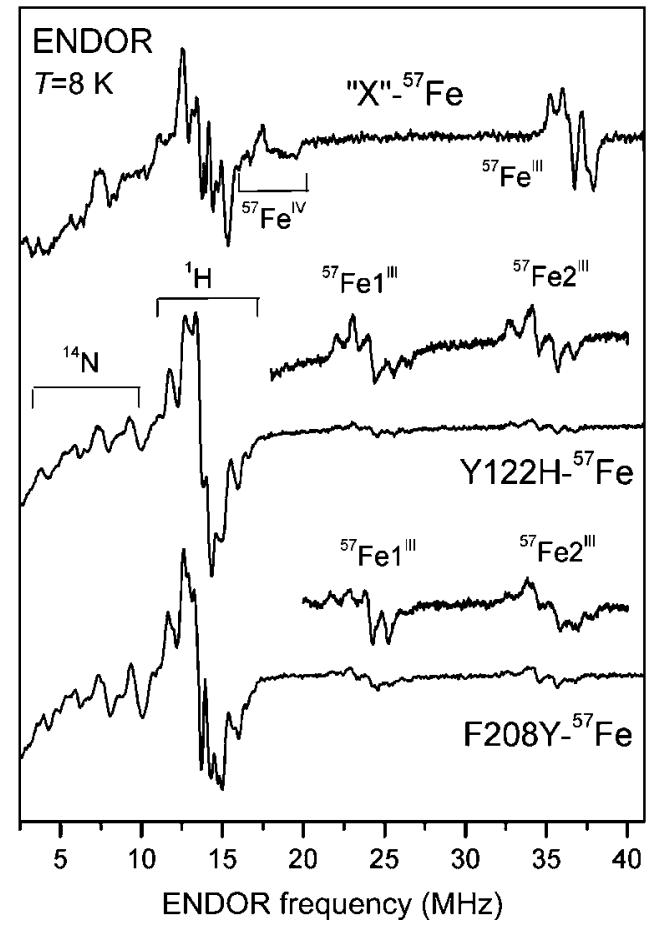

Figure $6{ }^{14} \mathrm{~N}-,{ }^{1} \mathrm{H}$ - and ${ }^{57} \mathrm{Fe}-\mathrm{ENDOR}$ spectra from the strongly coupled Fe"IIF"III-F208-O' center having a coordinated phenoxyl (tyrosyl) radical at $\mathrm{F} 208$ in $E$. coli $\mathrm{R} 2$ mutants $\mathrm{Y} 122 \mathrm{H}$ (Kolberg et al., 2005) and F208Y (Galander et al., unpublished results), in comparison with the spectra from the Fe'lIFelv intermediate ' $X$ ' from $E$. coli.

first group of lines at $35 \mathrm{MHz}$ and the deduced ${ }^{57} \mathrm{Fe} \mathrm{hf}-$ tensors agree very well with those of ${ }^{57} \mathrm{Fe} \mathrm{e}^{\mathrm{III}}$ in the spectrum of ' $X$ '. However, the second group of ${ }^{57} \mathrm{Fe}-\mathrm{ENDOR}$ lines at $24 \mathrm{MHz}$ is shifted significantly to higher frequencies compared to the group of ${ }^{57} \mathrm{Fe}^{\mathrm{IV}}$-lines in ' $\mathrm{X}$ (between 15 and $20 \mathrm{MHz}$; upper trace, Figure 6), and also shows smaller hyperfine anisotropy, which is typical for Fe $\mathrm{e}^{\text {III }}$ and not for Felv (Sturgeon et al., 1996). The paramagnetic center in $\mathrm{Y} 122 \mathrm{H}$ was shown to be made up by two Fe'II high-spin ions $(S=5 / 2)$ and a strongly coupled, most probably coordinated radical $(S=1 / 2)$, which couples to a total spin of $S=1 /{ }_{2}$. Such a radical diferric center was an early proposal for intermediate ' $X$ ' (Ravi et al., 1994), which was later assigned to a $\mathrm{Fe}^{\mathrm{II}} \mathrm{Fe} \mathrm{e}^{\mathrm{IV}}$ state (Sturgeon et al., 1996). The radical site in $\mathrm{Y} 122 \mathrm{H}$ was identified as oxidized phenoxyl (tyrosyl) radical F208-O^ using phenylalanine- $d_{8}$ isotope labeling and mass spectrometry (Kolberg et al., 2005).

Figure 6 (lowest trace) shows the ENDOR spectrum obtained from a sample of mutant F208Y enriched in ${ }^{57} \mathrm{Fe}$ (Galander et al., unpublished results). The entire spectrum, showing ${ }^{14} \mathrm{~N}-,{ }^{1} \mathrm{H}-$, and ${ }^{57} \mathrm{Fe}-E N D O R$ lines, is virtually identical to that for the $\mathrm{Y} 122 \mathrm{H}$ sample, indicating the

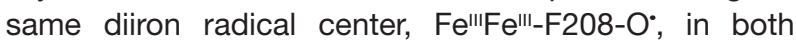
mutants.

There is a high structural similarity between the diiron centers in R2 of RNR and in the hydroxylase subunit of methane monooxygenase (MMO), for which reaction of the diferrous iron center with molecular oxygen leads to hydroxylation of the substrate methane (Baik et al., 2003). Apparently, small changes in the diiron ligand 
sphere can redirect the iron-oxygen reaction in RNR variants to result in hydrocarbon oxidation, as in $\mathrm{MMO}$ (Logan et al., 1998; Baldwin et al., 2001; Kolberg et al., 2005). A remarkable feature of the coupled radical iron centers Fe'IIIFelII-F208-O' formed in mutant RNR is their unusual stability (more than several weeks at room temperature). These centers show, however, no catalytic activity. Thus, hydroxylation and subsequent formation of a phenoxyl radical at F208, coordinated to Fe1, is apparently a wasteful second reaction pathway in RNR, which has to be carefully avoided in the native enzyme to maintain RNR function, i.e., generation of a catalytically active radical.

\section{A stable $\mathrm{Fe}^{\text {IIIFe }} \mathrm{Fe}^{\mathrm{IV}}$ center as functional replacement for the tyrosyl radical in RNR of C. trachomatis}

Recent studies on a new subform of class I RNR found in infectious bacteria such as Chlamydia trachomatis highlighted the importance of high-valent states of the diiron center. C. trachomatis RNR has a phenylalanine at the site corresponding to tyrosine Y122 in E. coli. Instead of a tyrosyl radical, a Fe"'IFelv state was observed by EPR and was proposed to play the role of the active species, triggering generation of the thiyl radical in subunit R1 of C. trachomatis RNR (Högbom et al., 2004). This proposal became even more reasonable by the finding that this $\mathrm{Fe}^{\text {IIIFelv }}$ species, which has a lifetime of only approximately $1 \mathrm{~s}$ in E. coli RNR, lives in C. trachomatis RNR for hours when the second subunit $\mathrm{R} 1$ and substrate are present (Voevodskaya et al., 2005). These results might indicate a newly identified role of the Fe'll'Felv state in other class I enzymes, where it is a long-known precursor of the tyrosyl radical in the reaction of the diferrous center with molecular oxygen, but might also be involved in mediating the radical transfer generating the thiyl radical in subunit $\mathrm{R} 1$ from the tyrosyl radical in $\mathrm{R} 2$.

\section{Studies on the mechanism of radical initiation in $\mathbf{R 1}$}

\section{Docking model of R1:R2 and proposed pathway of radical initiation}

A major unresolved question for the class I RNRs is the mechanism of radical initiation. How does a tyrosyl radical $\mathrm{Y} 122^{\circ}$ (E. coli numbering) in the R2 subunit generate a putative transient thiyl radical ( $\left.\mathrm{S}^{*}\right)$ on the $\mathrm{R} 1$ subunit located $35 \AA$ away (Uhlin and Eklund, 1994; Eklund et al., 2001; Stubbe et al., 2003)? E. coli and mouse RNRs are the most extensively studied of the class I RNRs. The active $E$. coli RNR is thought to be a 1:1 complex of the $R 1$ and $R 2(\alpha 2 \beta 2)$ subunits. $R 1$ is composed of two 85$\mathrm{kDa}$ monomers and $\mathrm{R} 2$ is composed of two $43.5-\mathrm{kDa}$ monomers (Figure 2). The active complex of the mouse RNR has been reported to have an $\alpha 2 \beta 2$ and $\alpha 6 \beta 6$ composition (Scott et al., 2001; Kashlan and Cooperman, 2003). Structures at atomic resolution of $E$. coli R1 (Uhlin and Eklund, 1994), and mouse (Nielsen et al., 1995; Strand et al., 2004), and yeast R2s (Voegtli et al., 2001; Sommerhalter et al., 2004) have been published. However, no structural data for an active complex of R1 and
R2 have yet been reported. Any model for the mechanism by which the $\mathrm{Y}_{122^{\circ}}$ on $\mathrm{R} 2$ generates an $\mathrm{S}^{\circ}$ on $\mathrm{R} 1$ is based on a docking model of the R1 and R2 subunits in a 1:1 transient complex proposed by Uhlin and Eklund (1994). This structural model is displayed in Figure 2.

While the interactions of the two proteins have been examined in detail (Thelander, 1973), re-examination of their interactions and lifetimes of the R1:R2 complex in the presence of substrate and allosteric effector is essential to elicit information on the radical initiation process. The present docking model used to envisage radical initiation is based on shape complementarity between the $\mathrm{R} 2$ and R1 surfaces and the presence of conserved residues of R2 that reside on the proposed R2 docking surface (Ekberg et al., 1998). In addition, the important observation that removal of the C-terminal tail (residues $6-30$ ) of R2s results in loss of R1/R2 interactions and the ability to reduce nucleotides, and that peptides of the Cterminal tail of R2 are competitive inhibitors of this interaction, also supports the proposed model (Climent et al., 1991, 1992). In both the E. coli and mouse RNRs (Lycksell et al., 1994) the interactions between $R 1$ and $R 2$ are weak, of the order of 0.1-0.2 $\mu \mathrm{M}$. The C-terminal ends of all R2s (the last 30-50 amino acids) are not observed in the X-ray structures due to their thermal lability (Lycksell and Sahlin, 1995). The last detectable amino acid is residue 340 in the $E$. coli $\mathrm{R} 2$. If the peptide bound to $\mathrm{R} 1$ adopts a conformation similar to that adopted by the Cterminus of $\mathrm{R} 2$ bound to $\mathrm{R} 1$, then a model results in which only 19 amino acids are missing and the distance between $\mathrm{Y}_{122^{\circ}}$ on $\mathrm{R} 2$ and the precursor $\mathrm{C} 439$ to the $\mathrm{S}^{\cdot}$ radical on $R 1$ is $35 \AA$. Nevertheless, a large structural void of $25 \AA$ remains between W48 on R2 and $\mathrm{Y} 731$ on R1. Furthermore, the essential Y356 residue is located in the C-terminus of R2, which is not visible in the structure.

Sjöberg, Gräslund and their collaborators (Uhlin and Eklund, 1994; Ekberg et al., 1996; Rova et al., 1999) proposed a radical initiation pathway over 10 essential residues:

$$
\begin{aligned}
\mathrm{Y} 122 & \rightarrow \mathrm{D} 84 \rightarrow \mathrm{Fe} 1 \rightarrow \mathrm{H} 118 \rightarrow \mathrm{D} 237 \rightarrow \mathrm{W} 48 \rightarrow \mathrm{Y} 356 \\
& \rightarrow \mathrm{Y} 731 \rightarrow \mathrm{Y} 730 \rightarrow \mathrm{C} 439
\end{aligned}
$$

The model suggests that communication between Y122 and C439 occurs via coupled electron-proton transfer along a conserved hydrogen-bonded chain on the proposed pathway. From the structure of R2 and the present docking model, identification of such a directly coordinated hydrogen-atom-transfer pathway is difficult (Stubbe et al., 2003). Theoretical calculations (Siegbahn et al., 1998) at the B3LYP level on selected model systems indicated that hydrogen atom transfer between $\mathrm{Y} 731$ and $\mathrm{Y} 730$ has a barrier of $20.5 \mathrm{~kJ} / \mathrm{mol}$ and of $33.9 \mathrm{~kJ} / \mathrm{mol}$ between $\mathrm{Y} 730$ and $\mathrm{C} 439$. Considering the performance of the B3LYP method in a variety of radical reactions, these barrier heights must be taken as lower bounds of the true barriers for the selected model systems (Lynch et al., 2000). A mechanistic model was proposed in which electron transfer from W48 to a hydroxyl ligand of the iron is coupled to separate abstraction of a hydrogen atom from a water ligand of the diiron cluster by Y122: Recently, the first direct experimental evidence 
for the chemical competence of amino acid intermediates in the postulated pathway and for the role of Y356 was reported (Chang et al., 2004).

The most intriguing feature of the mechanism of radical initiation is that it occurs only when the substrate and/or the allosteric effector are positioned on the R1 subunit ready for reduction. This raises the question as to whether any conformational change might trigger this mechanism. Recent pre-steady-state experiments (Ge et al., 2003) reported the observation that $Y 122^{\circ}$ is not lost under any conditions of turnover, in which the substrate, effector or $\mathrm{pH}$ are varied, on a time scale from $2 \mathrm{~ms}$ to seconds. On the other hand, the mechanistic model requires that $\mathrm{Y}_{122^{\circ}}$ is reduced and re-oxidized for the production of each dNDP. These results, in conjunction with pre-steady-state and steady-state turnover numbers for dCDP formation, revealed that the rate-determining step is a physical step prior to rapid nucleotide reduction and rapid tyrosine reoxidation to $\mathrm{Y} 122^{\circ}$. The data also indicated that the stoichiometry of dCDP formation is greater than the amount of $Y 122^{\circ}$ per $\mathrm{R} 2$ subunit. The last observation is puzzling, since it requires that one $\mathrm{Y} 122^{\circ}$ can activate both monomers of $\mathrm{R} 1$, and opens up a new layer of complexity into the mechanism of radical initiation. Further understanding of this mechanism requires experiments that are capable of detecting the formation of the postulated amino-acid intermediates on the $R 2 \rightarrow R 1$ pathway, as well as their population with respect to both homodimeric subunits.

\section{Radical probes to monitor distances and populations in R1:R2 with PELDOR spectroscopy}

Pulsed electron-electron double resonance (PELDOR) spectroscopy is a method that monitors weak dipoledipole interactions between the electron spins of radicals that span distances between approximately 15 and $80 \AA$ (Milov et al., 1998; Jeschke, 2002). This method provides a means to measure distances between R1 and R2 in frozen solution and in the presence of the substrate and allosteric effectors, if paramagnetic species can be specifically attached to R1 and R2, respectively. The advantage over X-ray crystallography is that experiments can be performed under physiologically relevant conditions, with a minimal radical-pair concentration required of approximately $20 \mu \mathrm{M}$ (Jeschke, 2002). Furthermore, the method gives access not only to distances, but also to the population of the radical pair, allowing the formation and destruction of radicals on a postulated pathway to be followed.

PELDOR was first used to perform a direct measurement of the distance between the two $\mathrm{Y} 122{ }^{\circ} \mathrm{s}$ on each monomer of R2 (Bennati et al., 2003). Since the early studies on class I RNR, it has been reported that R2 contains approximately one $\mathrm{Y} 122^{\circ}$ per homodimer. However, accurate spin quantitation indicated that the amount of radical slightly exceeds the $\mathrm{R} 2$ protein dimer concentration (Bollinger et al., 1991; Miller et al., 1999) and the distribution of these radicals in solution remains to be established. In Figure 7 we report echo-modulation traces of $Y 122^{\circ}$ in the $E$. coli enzyme compared to that from yeast, which contains only one $\mathrm{Y} 122^{\circ}$ per heterodimer. Only the E. coli R2 trace unambiguously shows an oscil-
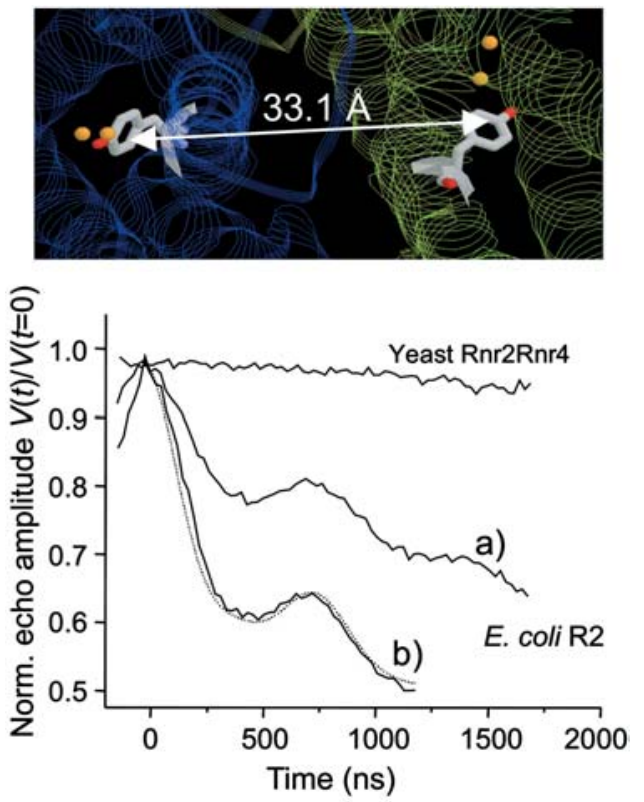

Figure 7 Normalized DEER traces of E. coli R2 and of Rnr2Rnr4 from yeast.

Traces (a) and (b) correspond to a microwave pump pulse duration of 32 ns (same for yeast Rnr2Rnr4) and 12 ns, respectively (Bennati et al., 2003). The oscillation corresponds to a distance of $33.1 \AA$. In the top part of the figure, the distance is illustrated as compared to the X-ray structure from Högbom et al. (2003).

lation on top of an exponential decay. This feature is indicative of a weak dipolar interaction between two or more $\mathrm{Y} 122^{\circ}$ radicals. Fourier transformation of the trace after baseline subtraction leads to a sharp oscillation frequency of $1.39 \pm 0.01 \mathrm{MHz}$ and a distance of $33.1 \AA$, which was interpreted as between the center of gravity of the spin density distributions. The distance is in excellent agreement with the distance between $Y 122$ on each protomer of R2 from the X-ray structure and single-crystal EPR studies (Nordlund et al., 1990; Högbom et al., 2003), and therefore the data provide evidence that $Y 122^{\circ}$ exists on both subunits of R2. A more quantitative evaluation of the modulation depth indicated that at least $25 \%$ of the $Y 122{ }^{\circ}$ s are paired in a sample, with a radical content of 1.2 Y122's per dimer. The method was also implemented at higher fields and frequencies (6 T, $180 \mathrm{GHz}$ ) and it was found that the observed orientational selectivity in the PELDOR modulation was consistent with the relative orientation of the two tyrosines as revealed by the X-ray structure (Denysenkov et al., 2005).

A method of producing stable radicals in $\mathrm{R} 1$, which can be used as spin probes in distance measurements, consists of incubating the enzyme with well-studied, mechanism-based inhibitors or mutants. For instance, reaction of class I RNR with the inhibitor 2'-azido-2'deoxyuridine5 '-diphosphate ( $\mathrm{N}_{3} \mathrm{UDP}$ ) leads to complete inactivation of the enzyme, loss of the tyrosyl radical and production of a stable nucleotide-based nitrogen-centered radical $\left(\mathrm{N}^{*}\right)$ (Thelander et al., 1976; Sjöberg et al., 1983; van der Donk et al., 1995), which is covalently attached to the sulfur of C225. The radical on $\mathrm{R} 1$ is stable on the minute time scale. The structure of $\mathrm{N}^{\bullet}$ has been debated in the literature over the past two decades. Based on extensive 


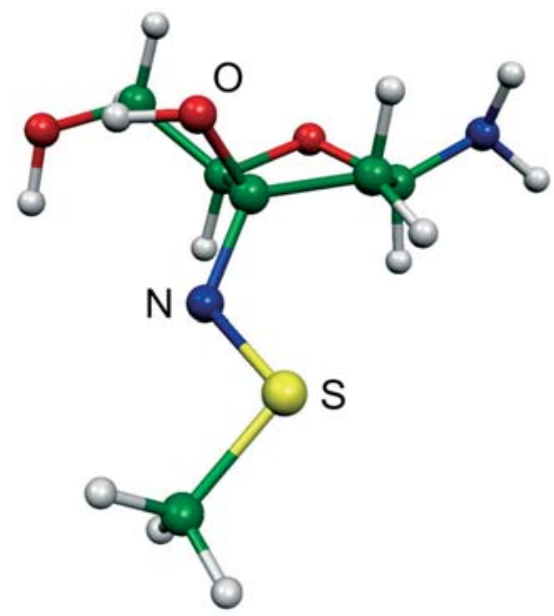

Figure 8 Structure of a model of the $\mathrm{N}^{*}$ radical from the reaction of class I RNR with $\mathrm{N}_{3} \mathrm{UDP}$ as obtained from the quantum chemical calculations of Fritscher et al. (2005).

Major spin densities are found in this $\mathrm{CN}^{\circ} \mathrm{S}$ type radical only at atoms labeled $\mathrm{N}$ and S; for details see Fritscher et al. (2005).

EPR studies, in conjunction with isotope labeling of the nucleotide and of the R1 protein, van der Donk et al. (1995) have proposed that $N^{*}$ is linked to C225 either via a CN'S or an ON'S type of structure. The availability of $3^{\prime}-\left[{ }^{17} \mathrm{O}\right]-\mathrm{N}_{3} \mathrm{UDP}$, in combination with EPR and DFT calculations, has recently permitted assignment of the structure of this species to a $\mathrm{CN} \cdot \mathrm{S}$ type radical and also provided evidence for trapping of a 3 '-ketonucleotide in the reduction mechanism of nucleotides (Fritscher et al., 2005). The structure of a model of the radical as optimized by DFT methods by Fritscher et al. (2005) is reported in Figure 8. The structure is well compatible with linking of the nucleotide to C225 on the bottom face, as revealed by comparison with the X-ray structure of R1 with bound substrate (Uhlin and Eklund, 1994).

\section{EPR distance measurements support a model for long-range radical initiation}

The reaction of $E$. coli class I RNR with the inhibitor $\mathrm{N}_{3}$ UDP was used to measure the distance between the subunits $R 1$ and R2 in the activated enzyme in frozen solution (Bennati et al., 2005). Although the reaction is accompanied by destruction of $\mathrm{Y} 122^{\circ}$, it was assumed that in R2s containing two $\mathrm{Y} 122^{\circ} \mathrm{s}$, only one radical might participate in the catalytic cycle. Therefore, the second radical could be used as a paramagnetic probe to monitor the distance to $\mathrm{N}^{*}$ in R1. This working hypothesis leads to the reaction scheme in Figure 9. We note that the PELDOR experiment detects only the R1:R2 complexes containing one paramagnetic pair. Thus, all R2s occupied by only one $\mathrm{Y} 122^{\circ}$, which in turn generates $\mathrm{N}^{*}$, do not contribute to the experiment.

Incubation of $E$. coli RNR with $\mathrm{N}_{3} \mathrm{UDP}$ and quenching after $60 \mathrm{~s}$ resulted in an EPR spectrum that contained $57 \% \mathrm{~N}^{*}$ and $43 \% \mathrm{Y}^{\circ} 2^{\circ}$ (Figure 10, top). The PELDOR time trace after subtraction of a mono-exponential decay (Figure 10, bottom) shows a weak oscillation. Analysis of the traces revealed a distance of $48.5 \pm 0.5 \AA$, which was assigned to the $\mathrm{N}^{*}-\mathrm{Y} 122^{\circ}$ cross-distance between the

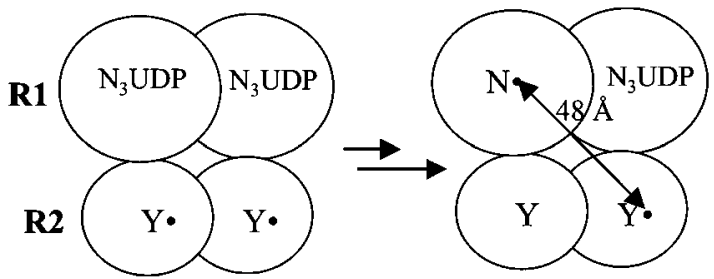

Figure 9 Model for radical distribution when R1:R2 is inactivated by $\mathrm{N}_{3}$ UDP.

(A) $\mathrm{N}_{3}$ UDP binds to each protomer of R1, which is in complex with R2. (B) The $\mathrm{Y}^{\cdot}$ on one protomer of R2 is reduced concomitant with generation of $\mathrm{N}^{*}$ from $\mathrm{N}_{3} \mathrm{UDP}$ on the symmetry-related protomer of R1.

subunits. Independent control experiments were also carried out to unambiguously exclude the possibility that the distance observed could arise from $\mathrm{N}^{*}$ pairs in each active site of the R1 homodimer. The distance measured was consistent with the docking model when the structure of $\mathrm{N}^{\bullet}$ was modeled into the $\mathrm{R} 1$ active site. Thus, the result rules out a large conformational change between $\mathrm{R} 1$ and R2 on formation of the active complex.

The long distance and the lack of any large conformational rearrangement support the proposed radical migration through a pathway involving aromatic amino acids over a distance of $35 \AA$ (Chang et al., 2004). Finally, the data gave evidence that only a single active site within $\mathrm{R} 1$ is occupied with $\mathrm{N}^{*}$. This behavior differs from the results of recent single-turnover, pre-steady-state exper-
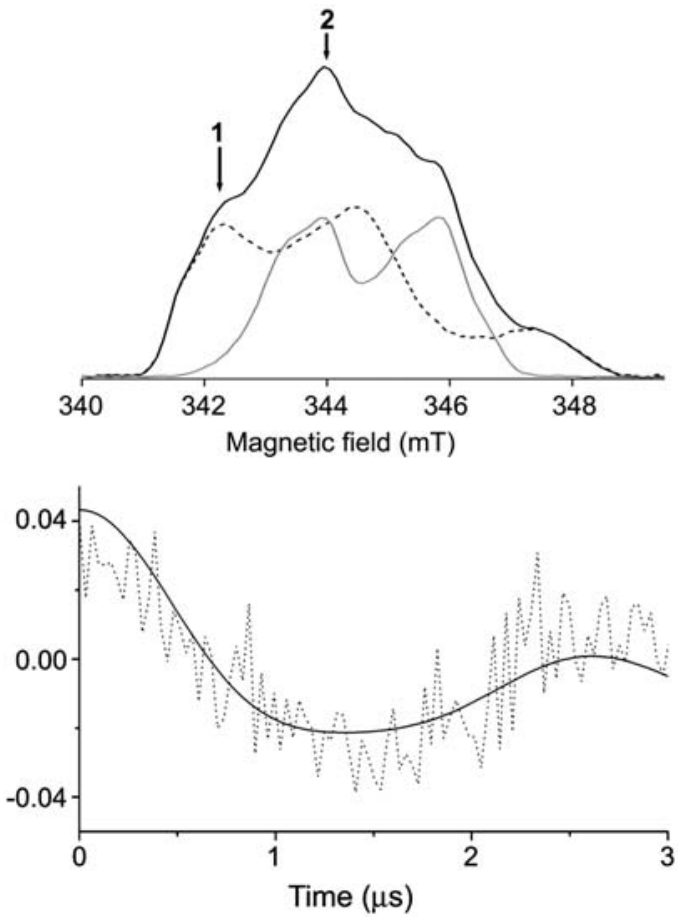

Figure 10 PELDOR experiment on the R1:R2 complex inactivated by $\mathrm{N}_{3} \mathrm{UDP}$.

Top: echo-detected EPR spectrum of the reaction mixture obtained after incubation of $E$. coli RNR with $\mathrm{N}_{3}$ UDP. Detection was performed on position 1 and pumping on position 2 of the EPR line. Bottom: three-pulse DEER trace after subtraction of a mono-exponential decay and simulation using a distancedomain Tikhonov regularization algorithm. 
iments (Ge et al., 2003), which showed that both monomers of $\mathrm{R} 1$ can produce dNDP with identical rate constants. The observation might be rationalized by considering that the inhibitor blocks RNR at the first turnover and a second dNDP cannot be produced. Furthermore, from the two available $\mathrm{Y} 122^{\circ}$ radicals on $\mathrm{R} 2$, only one seems to produce $\mathrm{N}^{*}$. This suggests a complex interplay of the subunits that permits electron transfer from a single $\mathrm{Y} 122^{\circ}$ in $\mathrm{R} 2$ to the active site of $\mathrm{R} 1$.

\section{Mechanism of the reduction of ribonucleotide in $\mathbf{R 1}$}

Over the years, various mechanistic hypotheses for elimination of the 2'-hydroxyl group from the ribonucleotide (Figure 1) have surfaced (Stubbe and van der Donk, 1998) that all invoke radicals as important intermediates in this process. This view is supported by the radical nature of the enzyme (see above), by a battery of results from mechanism-based inhibitor reactions (van der Donk et al., 1995; Covès et al., 1996; Fontecave, 1998), and by the outcome of studies with isotopically labeled compounds (Stubbe and Ackles, 1980; Stubbe et al., 1983) and with site-directed mutants (Mao et al., 1992a,b,c; Lawrence et al., 1999). Unfortunately, there is still no direct spectroscopic evidence for substrate radicals in the transformation of natural substrates by the wildtype enzyme. The strongest evidence, therefore, stems from the inactivation of RNR from $E$. coli with $(E)$ - and (Z)-2' - fluoromethylene-2'-deoxycytidine-5'-diphosphate, because EPR studies indicated that loss of the tyrosyl radical in $\mathrm{R} 2$ is accompanied by the formation of a new, substrate-based radical (van der Donk et al., 1996; Gerfen et al., 1998). Similarly, with 2 '-azido-2'-deoxyuridine5'-diphosphate ( $\left.\mathrm{N}_{3} \mathrm{UDP}\right)$, a stoichiometric mechanismbased inhibitor, the inactivation of RNR was accompanied by loss of the tyrosyl radical on the R2 subunit, concomitant with the formation of a new nitrogen-centered radical (van der Donk et al., 1995; Fritscher et al., 2005).
While the essential residues involved in the catalytic cycle have been identified through activity studies of sitedirected mutants (Mao et al., 1992a,b,c; Lawrence et al., 1999), the proximity of the most relevant residues, $\mathrm{Cys}_{225}$, $\mathrm{Cys}_{439}, \mathrm{Cys}_{462}, \mathrm{Glu}_{441}$, and $\mathrm{Asn}_{437}$, to the substrate C2' and C3' centers has been revealed through X-ray crystal structure analysis of the R1 protein with bound substrate (Uhlin and Eklund, 1994; Eriksson et al., 1997; Persson et al., 1997). These pieces of evidence were splendidly merged (Stubbe and van der Donk, 1998) with results from experiments on small model systems in homogeneous solution, indicating that the elimination of water can indeed be effected via a radical pathway. While older investigations focused on simple compounds, such as the dehydration of $\alpha, \beta$-dihydroxyalkanes (Steenken et al., 1986), later studies were able to shed light on the radicalbased dehydration of ribonucleotide-like models (Lenz and Giese, 1997). A currently widely accepted mechanistic model is shown in Figure 11.

The individual steps of the mechanism shown in Figure 11 have been proposed based on analogous reactions in homogenous solution and predict an intuitively attractive overall sequence of events. However, since most of the experimental results have been obtained by severely disturbing the natural enzymatic reaction using mutants or mechanism-based inhibitors, a critical step-by-step evaluation of the hitherto claimed 'evidence of mechanism' is certainly warranted.

\section{Step (1)}

All combined enzymatic, chemical and computational results suggest that the reductive elimination is initiated by the endothermic abstraction of the $3^{\prime}-\mathrm{H}$ at the ribonucleotide by the C439 thiyl radical (Stubbe and Ackles, 1980; Stubbe et al., 1983; Siegbahn, 1998; van der Donk et al., 1998). Despite all the technical problems involved in theoretical studies of negatively charged open-shell systems (Siegbahn, 1998; Mohr and Zipse, 1999), all small model studies of the initial hydrogen abstraction

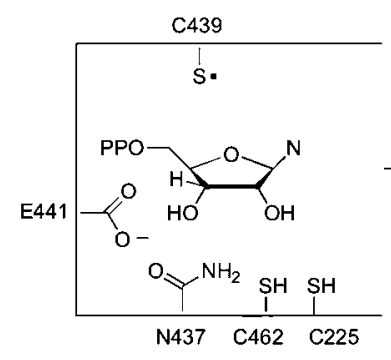

(1)
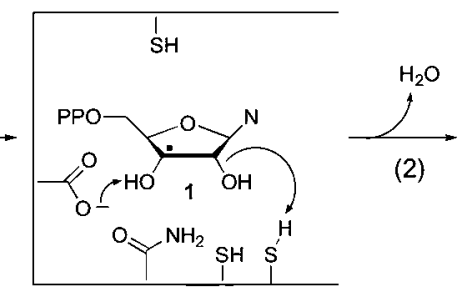

)

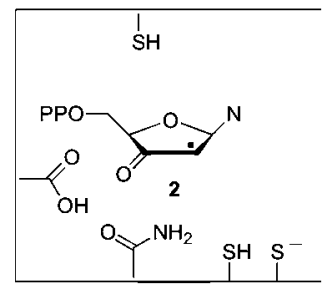

(3)
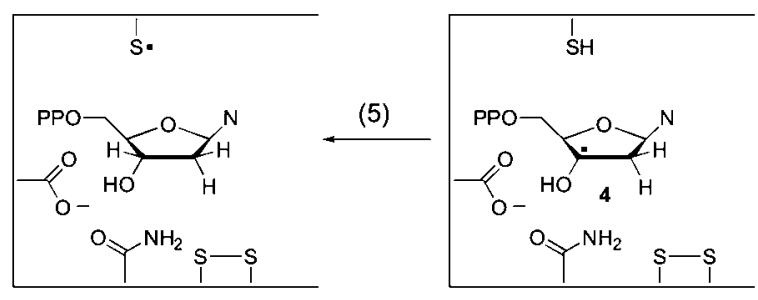

(4)

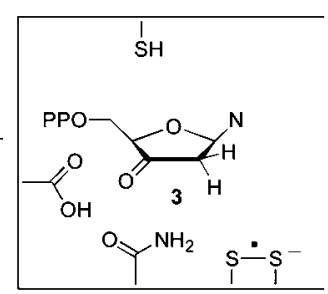

Figure 11 A currently widely accepted mechanism of the RNR-catalyzed reaction. 
step agree that this step is endothermic. Estimates based on experimentally measured heats of formation of methyl thiol and methanol radical put the endothermicity at 38-42 kJ/mol (Zipse, 2003). Reaction barriers for these small models are approximately $25 \mathrm{~kJ} / \mathrm{mol}$ higher. However, the reaction barrier and the reaction energy benefit significantly from coordination of the $\mathrm{C}^{\prime} \mathrm{OH}$ group to the negatively charged carboxylate group of E441, lowering the barrier by $12-17 \mathrm{~kJ} / \mathrm{mol}$ and the reaction energy by at least $8 \mathrm{~kJ} / \mathrm{mol}$ (Zipse, 2003; Pelmenschikov et al., 2004). The consideration of significantly larger parts of the substrate and the enzyme in theoretical studies has only recently been attempted (Cerqueira et al., 2004a; Pelmenschikov et al., 2004), with the result that the reaction barrier and reaction energy of the first step are much less favorable than found in small models. How far this finding is due to the constraints imposed onto the system will have to be investigated in future studies. However, even the most optimistic scenario describes the initial hydrogen abstraction step as energetically unfavorable, if not even rate-limiting for the overall substrate conversion. Reaction progress must therefore be driven by a subsequent, energetically more favorable reaction step.

\section{Steps (2) and (3)}

The elimination of water from the $3^{\prime}$-ribonucleotide radical to afford the $\alpha$-ketone radical 2 may occur via several distinct pathways, and the three most likely mechanisms are shown in Figure 12. Experimental differentiation between these three mechanistic options is quite difficult because all of them converge on the formation of the same final intermediate. One additional difficulty in estab- lishing a concise mechanism for step (2) is that all relevant functionalities $\left(2{ }^{\prime}-\right.$ and $\left.3^{\prime}-\mathrm{OH}\right)$ of the substrate may be modulated in their reactivity by hydrogen bonding, or partial or full proton transfer with groups C225, C462, $\mathrm{E} 441$, and N437 in the active site. In such a melange of mechanistic possibilities, it is strategically most helpful to eliminate first the most complex pathways (using Occam's razor) and second, those that have a high potential for undesired side reactions.

Pathway (2a) in Figure 12 invokes the occurrence of an intermediate distonic radical cation formed upon protonation of the 2'-OH group by the cysteine thiol, an early hypothesis in the field (Stubbe, 1989). The distonic radical cation was postulated to eliminate water to produce an enol radical cation. As enol radical cations are quite acidic (Röck and Schmittel, 1993; Schmittel, 1994), protonation of the E441 carboxylate group with the concomitant formation of a ketone radical would readily be explained. There are, however, two peremptory drawbacks to this reaction mode, as the initial proton transfer from a sulfhydryl group ( $\mathrm{p} K_{\mathrm{a}}=8.5$ ) to the 2 '-hydroxy functionality $\left(\mathrm{ROH}_{2}{ }^{+} \mathrm{pK} \cong-3\right)$ is strongly endergonic. This latter value is supported by theoretical estimates indicating closely similar acidities of protonated alcohols and structurally related distonic radical cations (Zipse, 1995). In homogeneous solution, protonation of the hydroxy group will only occur in rather acidic media. Moreover, enol radical cations are rather strong oxidants, irrespective of hydrogen bonding interactions (Lal et al., 2003); thus, the intermediate could also trigger undesired electron-transfer oxidation of the C225 thiolate that would be strongly exothermic.

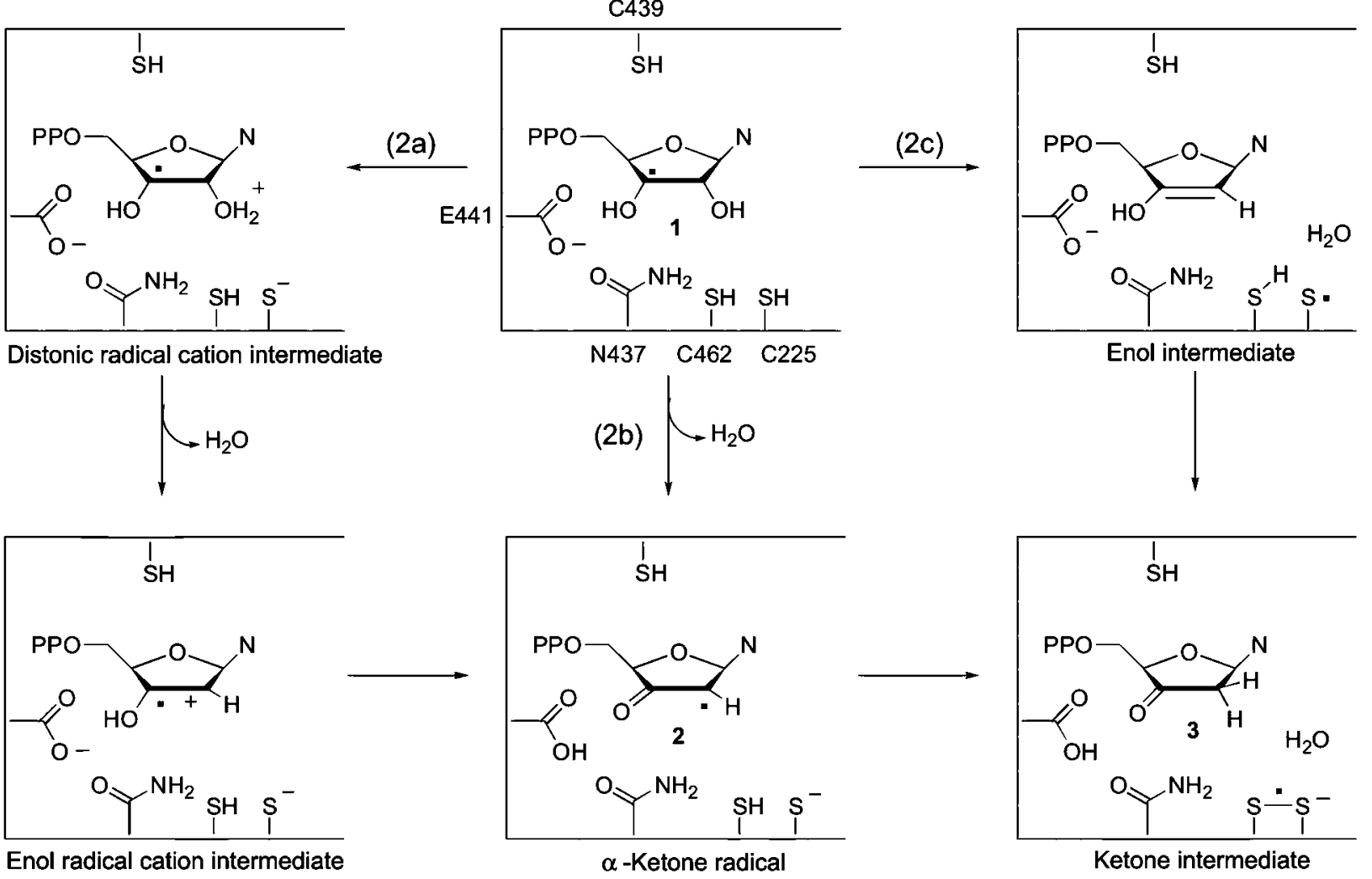

Figure 12 Various mechanistic options for the elimination of water, i.e., step (2). 
Pathway (2b), involving simultaneous acid/base-catalyzed dehydration, has evolved as the currently favored mechanism. The concept was first introduced by Zipse (1995), who suggested that a protonated glutamate could act as a bifunctional catalyst. A variation of this theme using only neutral molecules to avoid charge separation was computationally investigated slightly later (Siegbahn, 1998), but the experimental $\mathrm{pH}$ dependence of the enzyme activity (Persson et al., 1997), showing highest activity at $\mathrm{pH} 8$, is more suggestive of the involvement of $\mathrm{E} 441$ in its deprotonated form $\left[\mathrm{p} \mathrm{K}_{\mathrm{a}(\mathrm{Glu}-\mathrm{COOH})}=4.4\right]$. At about the same time, Zipse's hypothesis was refined by Stubbe and van der Donk (1998), who postulated that the E441 carboxylate group abstracts the proton at $3^{\prime}-\mathrm{OH}$ simultaneously with the protonation of $2^{\prime}-\mathrm{OH}$ by $\mathrm{C} 225$, leading to facile dehydration. Such a concerted process would be most suited to provide the least amount of side reactions by avoiding high-energy substrate derivatives such as ion radical intermediates. Recent theoretical studies including E441 in its anionic form predict a free energy barrier of $+43.9 \mathrm{~kJ} / \mathrm{mol}$ and a reaction free energy of $+29.7 \mathrm{~kJ} / \mathrm{mol}$ for this step (Cerqueira et al., 2004b). This proposal is currently only in conflict with the EPR detection of a disulfide radical anion in the reaction of a E441Q R1 mutant (Lawrence et al., 1999), as a glutamine in position 441 would not be able to promote efficient acid/ base-catalyzed dehydration. A way out of this predicament requires an alternative pathway for the E441Q R1 mutant to generate the disulfide radical anion that is independent of the elimination reaction.

Pathway (2b) can also be formulated in a stepwise manner, involving first deprotonation of the $\mathrm{C}^{\prime}$ ' hydroxyl group through E441 and subsequent elimination of the C2' hydroxyl group to yield the $\alpha$-ketone radical 2 . This mechanism has evolved from model studies in homogeneous solution under mild general-base catalysis conditions (Lenz and Giese, 1997). In addition, $\alpha$-eliminations of ketyl radical anions are rapid and efficient processes widely applied in synthesis (Schmittel and Ghorai, 2001). However, while solution studies clearly favor the radical anion mechanism due to its lower barrier than the radical cation variant (Lenz and Giese, 1997), results from mutants of $E$. coli argue strongly against a stepwise radical anion mechanism (Persson et al., 1997). In an E441Q R1 mutant study, Stubbe and colleagues shut down the deprotonation pathway for the 3 '-ribonucleotide radical by exchanging E441 (glutamate) with Q441 (glutamine), but formation of the disulfide radical anion was observed nevertheless (Lawrence et al., 1999). Also, the formation of a ketyl radical anion intermediate in the enzyme active site would bring about two additional problems. Most importantly, ketyl radical anions are very strong reducing agents, the reduction power of which cannot be substantially alleviated through hydrogen bonding (Oelgemöller et al., 2001, 2002). Hence, the possibility arises that electron transfer into the protein backbone would lead to significant side reactions, competing to some extent with the desired release of hydroxide in the $\alpha$-position. Moreover, a stepwise process suggests that a freely diffusing hydroxide is liberated. While it is highly likely that mostly the C225 sulfhydryl is targeted for proton transfer, there is also a chance that E441 is depro- tonated. Both the base-catalyzed pathway (2b) and the acid-catalyzed pathway (2a) assume that $\alpha$-ketone radical 2 is trapped in the subsequent step (3) through hydrogen atom transfer from C225, yielding ketone $\mathbf{3}$ as a closed-shell reaction intermediate.

Pathway (2c), involving homolytic elimination of the $\mathrm{C} 2$ '-OH group and concerted hydrogen abstraction of the incipient hydroxyl radical from the thiol group of C225, has recently emerged from theoretical studies of extended model systems (Pelmenschikov et al., 2004). In contrast to pathways (2a) and (2b), a neutral substrate enol intermediate is now generated as the primary reaction product, together with a water molecule situated directly below the enol substrate and a thiyl radical at the C225 position. Generation of the closed-shell ketone intermediate 3 in step 3 now only requires reshuffling of the hydrogen bonding network of the active site. That the substituent connected to the C2' carbon atom is cleaved homolytically has previously not been assumed to be relevant for the natural substrates of RNR enzymes, but represents the default pathway in model reactions performed in apolar solvents on substrates carrying a C2' leaving group, such as thiol (Pereira et al., 2005), phenylsulfinyl (Robins et al., 1999), or halides (Robins et al., 1996). For disulfide substituents in the C2' position, experimental and computational studies are suggestive of homolytic cleavage, even in the enzyme-catalyzed reaction (Covès et al., 1996; Pereira et al., 2005). However, even for halides, the influence of a polar, hydrogenbonding environment may be substantial enough to force the heterolytic elimination mechanism favored in the enzyme-catalyzed transformation (Harris et al., 1984; Fernandes and Ramos, 2003). Extensive work on the reaction of $\mathrm{N}_{3}$ UDP with wild-type enzyme (Salowe et al., 1993; van der Donk et al., 1995) can be rationalized by either the anionic release of azide (Pereira et al., 2003) or by initial homolytic generation of an azide radical and subsequent reduction to azide, in both cases followed by a sequence of $\mathrm{N}_{2}$ elimination and addition to the C3' carbon atom. The $\mathrm{N}$-centered radical generated in this latter step has only recently been characterized through a combination of high-field EPR spectroscopy and DFT calculations (Fritscher et al., 2005).

\section{Step (4)}

The involvement of the disulfide radical anion is still a strongly debated element of RNR catalysis (Cerqueira et al., 2004b), but all features of the mechanism are in good agreement with findings from chemical models. For example, disulfide radical anions are well known from pulse radiolysis studies, although their lifetime in water is usually very short, being in the microsecond regime (Hoffman et al., 1972). A common approach to disulfide radical anions is by a combination of $\mathrm{RS}^{\circ}$ and $\mathrm{RS}^{-}$, as this reaction is nearly diffusion-controlled in aqueous solution, a reaction now postulated to occur in the active site. Equilibrium constants for this association reaction are in the range $10^{2}-10^{4} \mathrm{M}^{-1}$ (Mezyk and Armstrong, 1999). Direct evidence for the reaction of the thiyl radical and thiolate to the disulfide radical anion was recognized by EPR in the enzymatic process, at least for the E441Q R1 mutant (Lawrence et al., 1999). The reduction potentials 


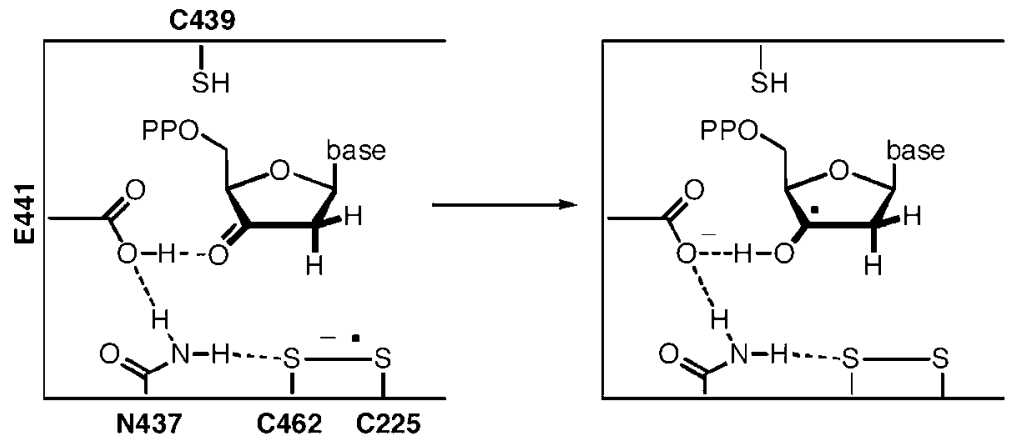

Figure 13 Step (4) as suggested by Cerqueira et al. (2004b) and by Pelmenschikov et al. (2004).

of disulfides are in the range of -1.9 to $-2.3 \mathrm{~V}_{\mathrm{SCE}}$ for dialkyl derivatives (Mezyk and Armstrong, 1999; Antonello et al., 2002); hence, disulfide radical anions are strong reducing agents that can reduce carbonyl derivatives, in particular if these are involved in hydrogen bonding (Oelgemöller et al., 2002).

As such, the only major problem is to rationalize the proton-coupled electron transfer depicted in step (4). An earlier suggestion by Persson et al. (1997) was recently refined by others (Cerqueira et al., 2004b; Pelmenschikov et al., 2004). Accordingly, reduction of the 3 '-ketodeoxynucleotide proceeds in a single step involving protoncoupled electron transfer through oxidation of the disulfide radical anion and deprotonation of E441. This electron transfer process is facilitated by the presence of N437 (Kasrayan et al., 2002) (Figure 13). In addition, it was suggested that the biological role of the disulfide bridge is to keep the substrate from diffusing into solution. Hence, the product may only be liberated after reduction of the disulfide.

\section{Step (5)}

The last step of the whole sequence is undisputed, as it is exothermic and the reverse of the initial step (1). The change in substrate structure at the $\mathrm{C}^{\prime}$ ' position appears to have hardly any influence on the reaction barrier and reaction energy. The exothermicity of this last step has been estimated at approximately $-23 \mathrm{~kJ} / \mathrm{mol}$ (Cerqueira et al., 2004b; Pelmenschikov et al., 2004).

In conclusion, many constituents of the mechanism of the catalytic deoxygenation of ribonucleotides promoted by RNR seem to be settled to a large extent. It is helpful to realize that RNR has been able to teach radical and radical ion chemists a lesson about the utility of coupling dissociation processes, such as dehydration of the $3^{\prime}-$ ribonucleotide radical, and reduction processes, such as reduction of the 3'-ketonucleotide by the disulfide radical anion, to hydrogen bonding to lower their barriers significantly. The transfer of such concepts into preparative radical and radical ion chemistry is still in its infancy.

\section{Acknowledgments}

The authors gratefully acknowledge the financial support of their research programs related to ribonucleotide reductase through the 'Radicals in Enzymatic Catalysis' priority program (SPP 1071) of the Deutsche Forschungsgemeinschaft and thank their previous and present coworkers and colleagues within this program, whose contributions are evident from the references. F.L. thanks G. Lassmann for a successful collaboration during the early time of the priority program. R. Bittl and T. Prisner are thanked for instrumental support. Fruitful and longstanding external cooperations with J. Stubbe (M.B.), A. Gräslund, P. Nordlund, and B.M. Sjöberg (F.L.) were the basis for the authors' own experimental work presented.

\section{References}

Andersson, M.E., Högbom, M., Rinaldo-Matthis, A., Andersson, K.K., Sjöberg, B.M., and Nordlund, P. (1999). The crystal structure of an azide complex of the diferrous R2 subunit of ribonucleotide reductase displays a novel carboxylate shift with important mechanistic implications for diiron-catalyzed oxygen activation. J. Am. Chem. Soc. 121, 2346-2352.

Antonello, S., Benassi, R., Gavioli, G., Taddei, F., and Maran, F. (2002). Theoretical and electrochemical analysis of dissociative electron transfers proceeding through formation of loose radical anion species: reduction of symmetrical and unsymmetrical disulfides. J. Am. Chem. Soc. 124, 75297538.

Atkin, C.L., Thelander, L., Reichard, P., and Lang, G. (1973). Iron and free radical in ribonucleotide reductase - exchange of iron and Mössbauer spectroscopy of protein B2 subunit of Escherichia coli enzyme. J. Biol. Chem. 248, 7464-7472.

Baik, M.-H., Newcomb, M., Friesner, R.A., and Lippard S.J. (2003). Mechanistic studies on the hydroxylation of methane by methane monooxygenase. Chem. Rev. 103, 2385-2419.

Baldwin, J., Krebs, C., Ley, B.A., Edmondson, D.E., Huynh, B.H., and Bollinger, J.M. (2000). Mechanism of rapid electron transfer during oxygen activation in the R2 subunit of Escherichia coli ribonucleotide reductase. 1. Evidence for a transient tryptophan radical. J. Am. Chem. Soc. 122, 1219512206.

Baldwin, J., Voegtli, W.C., Khidekel, N., Moenne-Lopez, P., Krebs, C., Pereira, A.S., Ley, B.A., Huynh, B.H., Loehr, T.M., Riggs-Gelasco, P.J., et al. (2001). Rational reprogramming of the R2 subunit of Escherichia coli ribonucleotide reductase into a self-hydroxylating monooxygenase. J. Am. Chem. Soc. 123, 7017-7030.

Baldwin, J., Krebs, C, Saleh, L., Stelling, M., Huynh, B.H., Bollinger, J.M., and Riggs-Gelasco, P.J. (2003). Structural characterization of the peroxodiiron(III) intermediate generated during oxygen activation by the W48A/D84E variant of ribonucleotide reductase protein R2 from Escherichia coli. Biochemistry 42, 13269-13279

Bar, G., Bennati, M., Nguyen, H.H.T., Stubbe, J., and Griffin, R.G. (2001). High-frequency $(140 \mathrm{GHz})$ time domain EPR and ENDOR spectroscopy: the tyrosyl radical-diiron cofactor in ribonucleotide reductase from yeast. J. Am. Chem. Soc. 123, 3569-3576. 
Bennati, M., Farrar, C.T., Bryant, J.A., Inati, S.J., Weis, V., Gerfen, G.J., Riggs-Galesco, P., Stubbe, J., and Griffin, R.G. (1999). Pulsed electron-nuclear double resonance (ENDOR) at $140 \mathrm{GHz}$. J. Magn. Reson. 138, 232-243.

Bennati, M., Stubbe, J., and Griffin, R.G. (2001). High-frequency EPR and ENDOR: time-domain spectroscopy of ribonucleotide reductase. Appl. Magn. Res. 21, 389-410.

Bennati, M., Weber, A., Antonic, J., Perlstein, D.L., Robblee, J., and Stubbe, J. (2003). Pulsed ELDOR spectroscopy measures the distance between the two tyrosyl radicals in the $\mathrm{R} 2$ subunit of the $E$. coli ribonucleotide reductase. J. Am. Chem. Soc. 125, 14988-14989.

Bennati, M., Robblee, J.H., Mugnaini, V., Stubbe, J., Freed, J., and Borbat, P. (2005). EPR distance measurements support a model for long range radical initiation. J. Am. Chem. Soc., in press.

Bleifuß, G., Kolberg, M., Pötsch, S., Hofbauer, W., Bittl, R., Lubitz, L., Gräslund, A., Lassmann, G., and Lendzian, F. (2001). Tryptophan and tyrosyl radicals in ribonucleotide reductase: a comparative high-field EPR study at $94 \mathrm{GHz}$. Biochemistry 40, 15362-15368.

Bollinger, J.M. Jr., Edmondson, D.E., Huynh, B.H., Filley, J., Norton, J.R., and Stubbe, J. (1991). Mechanism of assembly of the tyrosyl radical-dinuclear iron cluster cofactor of ribonucleotide reductase. Science 253, 292-298.

Bollinger, J.M. Jr., Tong, W.H., Ravi, N., Huynh, B.H., Edmondson, D.E., and Stubbe, J. (1994a). Mechanism of assembly of the tyrosyl radical-diiron(III) cofactor of $E$. coli ribonucleotide reductase. 2. Kinetics of the excess $\mathrm{Fe}^{2+}$ reaction by optical, EPR, and Mössbauer spectroscopies. J. Am. Chem. Soc. 116, 8015-8023.

Bollinger, J.M. Jr., Tong, W.H., Ravi, N., Huynh, B.H., Edmondson, D.E., and Stubbe, J. (1994b). Mechanism of assembly of the tyrosyl radical-diiron(III) cofactor of $E$. coli ribonucleotide reductase. 3. Kinetics of the limiting $\mathrm{Fe}^{2+}$ reaction by optical, EPR, and Mössbauer spectroscopies. J. Am. Chem. Soc. 116, 8024-8032.

Cerqueira, N.M.F.S.A., Fernandes, P.A., Eriksson, L.A., and Ramos, M.J. (2004a). Ribonucleotide activation by enzyme ribonucleotide reductase: understanding the role of the enzyme. J. Comp. Chem. 25, 2031-2037.

Cerqueira, N.M.F.S.A., Fernandes, P.A., Eriksson, L.A., and Ramos, M.J. (2004b). New insights into a critical biological control step of the mechanism of ribonucleotide reductase. J. Mol. Struct. Theochem. 709, 53-65.

Chang, M.C.Y., Yee, C.S., Stubbe, J., and Nocera, D.G. (2004). Turning on ribonucleotide reductase by light-initiated amino acid radical generation. Proc. Natl. Acad. Sci. USA 101, $6882-6887$.

Climent, I., Sjöberg, B.-M., and Huang, C.Y. (1991). Carboxylterminal peptides as probes for $E$. coli ribonucleotide reductase subunit interaction: kinetic analysis of inhibition studies. Biochemistry 30, 5164-5171.

Climent, I., Sjöberg, B.-M., and Huang, C.Y. (1992). Site-directed mutagenesis and deletion of the carboxyl terminus of $E$. coli ribonucleotide reductase protein $\mathrm{R} 2$. Effects on catalytic activity and subunit interaction. Biochemistry $31,4801-4807$.

Covès, J., de Fallois, L.L.H., Le Pape, L., Décout, J.-L., and Fontecave, M. (1996). Inactivation of Escherichia coli ribonucleotide reductase by $2^{\prime}$-deoxy-2'-mercaptouridine $5^{\prime}$-diphosphate. Electron paramagnetic resonance evidence for a transient protein perthiyl radical. Biochemistry 35, 8595-8602.

Denysenkov, V., Prisner, T.F., Stubbe, J., and Bennati, M. (2005). High frequency $180 \mathrm{GHz}$ PELDOR. Appl. Magn. Reson., in press.

Dong, Y. and Que, L. Jr. (1995). An exchange-coupled complex with localized high-spin FelV and Felll sites of relevance to cluster X of Escherichia coli ribonucleotide reductase. J. Am. Chem. Soc. 117, 11377-11378.

Ehrenberg, A. and Reichard, P. (1972). Electron-spin resonance of iron-containing protein $\mathrm{B} 2$ from ribonucleotide reductase. J. Biol. Chem. 247, 3485-3488.
Ekberg, M., Sahlin, M., Eriksson, M., and Sjöberg, B.-M. (1996). Two conserved tyrosine residues in protein R1 participate in an intermolecular electron transfer in ribonucleotide reductase. J. Biol. Chem. 271, 20655-20659.

Ekberg, M., Pötsch, S., Sandin, E., Thunnissen, M., Nordlund, P., Sahlin, M., and Sjöberg, B.-M. (1998). Preserved catalytic activity in an engineered ribonucleotide reductase R2 protein with a nonphysiological radical transfer pathway. J. Biol. Chem. 272, 21003-21008.

Eklund, E., Uhlin, U., Farnegardh, M., Logan, D.T., and Nordlund, P. (2001). Structure and function of the radical enzyme ribonucleotide reductase. Prog. Biophys. Mol. Biol. 77, 177-268.

Engström, M., Himo, F., Gräslund, A., Minaev, B., Vahtras, O., and Agren, H. (2000). Hydrogen bonding to tyrosyl radical analyzed by ab initio $g$-tensor calculations. J. Phys. Chem. A 104, 5149-5153.

Eriksson, M., Uhlin, U., Ramaswamy, S., Ekberg, M., Regnstrom, K., Sjöberg, B.-M., and Eklund, H. (1997). Binding of allosteric effectors to ribonucleotide reductase protein $\mathrm{R} 1$ : reduction of active-site cysteines promotes substrate binding. Structure 5, 1077-1092.

Fernandes, P.A. and Ramos, M.J. (2003). Theoretical studies on the mode of inhibition of ribonucleotide reductase by 2 '-substituted substrate analogues. Chem. Eur. J. 9, 5916-5925.

Fontecave, M. (1998). Ribonucleotide reductases and radical reactions. Cell. Mol. Life Sci. 54, 684-695.

Fontecave, M., Mulliez, E., and Logan, D.T. (2002). Deoxyribonucleotide synthesis in anaerobic microorganisms: the class III ribonucleotide reductase. Prog. Nucleic Acid Res. 72, 95-127.

Fritscher, J., Artin, E., Wnuk, S., Bar, G., Robblee, J.H., Kacprzak, S., Kaupp, M., Griffin, R.G., Bennati, M., and Stubbe, J. (2005). Structure of the nitrogen-centered radical formed during inactivation of $E$. coli ribonucleotide reductase by 2'-azido-2'-deoxyuridine-5'-diphosphate: trapping of the $3^{\prime}$ ketonucleotide. J. Am. Chem. Soc. 127, 7729-7738.

Ge, J., Yu, G., Ator, M.A., and Stubbe. J. (2003). Pre-steadystate and steady-state kinetic analysis of $E$. coli class I ribonucleotide reductase. Biochemistry 42, 10071-10083.

Gerfen, G.J., Bellew, B.F., Un, S., Bollinger, J.M. Jr., Stubbe, J., Griffin, R.G., and Singel, D.J. (1993). High-frequency EPR spectroscopy of the tyrosyl radical in $E$. coli ribonucleotide reductase. J. Am. Chem. Soc. 115, 6420-6421.

Gerfen, G.J., van der Donk, W.A., Yu, G., McCarthy, J.R., Jarvi, E.T., Matthews, D.P., Farrar, C., Griffin, R.G., and Stubbe, J. (1998). Characterization of a substrate-derived radical detected during the inactivation of ribonucleotide reductase from Escherichia coli by 2'-fluoromethylene-2'-deoxycytidine 5'-diphosphate. J. Am. Chem. Soc. 120, 3823-3835.

Harris, G., Ator, M., and Stubbe, J. (1984). Mechanism of inactivation of Escherichia coli and Lactobacillus leichmannii ribonucleotide reductases by 2 '-chloro-2'-deoxynucleotides: evidence for generation of 2-methylene-3(2H)-furanone. Biochemistry 23, 5214-5225.

Han, W.G., Lovell, T., Liu, T., and Noodleman, L. (2004). Density functional study of a $\mu-1,1$-carboxylate bridged $\mathrm{Fe}(\mathrm{III})-\mathrm{O}-$ $\mathrm{Fe}(\mathrm{IV})$ model complex. 2. Comparison with ribonucleotide reductase intermediate X. Inorg. Chem. 43, 613-621.

Himo, H., Gräslund, A., and Eriksson, L.A., (1997). Density functional calculations on model tyrosyl radicals. Biophys. J. 72 , 1556-1567.

Hoffman, M.Z. and Hayon, E. (1972). One-electron reduction of disulfide linkage in aqueous-solution - formation, protonation, and decay kinetics of RSSR-radical. J. Am. Chem. Soc. 94, 7950-7957.

Hoganson, C.W., Sahlin, M., Sjöberg, B.-M., and Babcock, G.T. (1996). Electron magnetic resonance of the tyrosyl radical in ribonucleotide reductase from $E$. coli. J. Am. Chem. Soc. 118, 4672-4679.

Högbom, M., Galander, M., Andersson, M., Kolberg, M., Hofbauer, W., Lassmann, G., Nordlund, P., and Lendzian, F. (2003). Displacement of the tyrosyl radical cofactor in ribo- 
nucleotide reductase obtained by single-crystal high-field EPR and 1.4-Å X-ray data. Proc. Natl. Acad. Sci. USA 100, 3209-3214.

Högbom, M., Stenmark, P., Voevodskaya, N., McClarty, G., Gräslund, A., and Nordlund, P. (2004). The radical site in chlamydial ribonucleotide reductase defines a new R2 subclass. Science 305, 245-248.

Jeschke, G. (2002). Determination of the nanostructure of polymer materials by electron paramagnetic resonance spectroscopy. Macromol. Rapid Commun. 23, 227-246.

Kashlan, O.B. and Cooperman, B.S. (2003). Comprehensive model for allosteric regulation of mammalian ribonucleotide reductase: refinements and consequences. Biochemistry 42 , 1696-1706.

Kasrayan, A., Persson, A.L., Sahlin, M., and Sjöberg, B.M. (2002). The conserved active site asparagine in class I ribonucleotide reductase is essential for catalysis. J. Biol. Chem. 277, 5749-5755.

Kolberg, M., Strand, K.R., and Andersson, K.K. (2004). Structure, function and mechanism of ribonucleotide reductases. Biochim. Biophys. Acta 1699, 1-34.

Kolberg, M., Logan, D.T., Bleifuss, G., Pötsch, S., Sjöberg, B.M., Gräslund, A., Lubitz, W., Lassmann, G., and Lendzian, F. (2005). A new tyrosyl radical on Phe208 as ligand to the diiron center in Escherichia coli ribonucleotide reductase, mutant Y122H. J. Biol. Chem. 280, 11233-11246.

Krebs, C., Chen, S., Baldwin, J., Ley, B.A., Patel, U., Edmondson, D.E., Huynh, B.H., and Bollinger, J.M. Jr. (2000). Mechanism of rapid electron transfer during oxygen activation in the R2 subunit of Escherichia coli ribonucleotide reductase. 2. Evidence for and consequences of blocked electron transfer in the W48F variant. J. Am. Chem. Soc. 122, 1220712219.

Lal, M., Langels, A., Deiseroth, H.-J., Schlirf, J., and Schmittel, M. (2003). Role of hydrogen bonding in the oxidation potential of enols. J. Phys. Org. Chem. 16, 373-379.

Lawrence, C.C., Bennati, M., Obias, H.V., Bar, G., Griffin, R.G., and Stubbe, J. (1999). High-field EPR detection of a disulfide radical anion in the reduction of cytidine $5^{\prime}$-diphosphate by the E441Q R1 mutant of Escherichia coli ribonucleotide reductase. Proc. Natl. Acad. Sci. USA 96, 8979-8984.

Lendzian, F. (2005). Structure and interactions of amino acid radicals in class I ribonucleotide reductase studied by ENDOR and high-field EPR spectroscopy. Biochim. Biophys. Acta 1707, 67-90.

Lendzian, F., Sahlin, M., MacMillan, F., Bittl, R., Fiege, R., Pötsch, S., Sjöberg, B.-M., Gräslund, A., Lubitz, W., and Lassmann, G. (1996). Electronic structure of neutral tryptophan radicals in ribonucleotide reductase studied by EPR and ENDOR spectroscopy. J. Am. Chem. Soc. 118, 8111-8120.

Lenz, R. and Giese, B. (1997). Studies on the mechanism of ribonucleotide reductases. J. Am. Chem. Soc. 119, 27842794.

Licht, S., Gerfen, G.J., and Stubbe, J. (1996). Thiyl radicals in ribonucleotide reductases. Science 271, 477-481.

Ling J., Sahlin M., Sjöberg, B.M., Loehr, T.M., and SandersLoehr, J. (1994). Dioxygen is the source of the $\mu$-oxo bridge in iron ribonucleotide reductase. J. Biol. Chem. 269, 5595-5601.

Liu, A., Sahlin, M., Pötsch, S., Sjöberg, B.-M., and Gräslund, A. (1998). New paramagnetic species formed at the expense of the transient tyrosyl radical in mutant protein R2 F208Y of Escherichia coli ribonucleotide reductase. Biochem. Biophys. Res. Commun. 246, 740-745.

Liu, A.M., Barra, A.L., Rubin, H., Lu, G.Z., and Gräslund, A. (2000). Heterogeneity of the local electrostatic environment of the tyrosyl radical in Mycobacterium tuberculosis ribonucleotide reductase observed by high-field electron paramagnetic resonance. J. Am. Chem. Soc. 122, 1974-1978.
Logan, D.T., DeMare, F., Persson, B.O., Slaby, A., Sjöberg, B.M., and Nordlund, P. (1998). Crystal structures of two selfhydroxylating ribonucleotide reductase protein R2 mutants: structural basis for the oxygen-insertion step of hydroxylation reactions catalyzed by diiron proteins. Biochemistry 37 , 10798-10807.

Lycksell, P.-O. and Sahlin, M. (1995). Demonstration of segmental mobility in the functionally essential carboxyl terminal part of ribonucleotide reductase protein R2 from $E$. coli. FEBS Lett. 368, 441-444.

Lycksell, P.-O., Ingemarson, R., Davis, R., Gräslund, A., and Thelander, L. (1994). ${ }^{1} \mathrm{H}$ NMR studies of mouse ribonucleotide reductase: the R2 protein carboxyl-terminal tail, essential for subunit interaction, is highly flexible but becomes rigid in the presence of protein R1. Biochemistry 33, 2838-2842.

Lynch, B.J., Fast, P.L., Harris, M., and Truhlar, D.G. (2000). Adiabatic connection for kinetics. J. Phys. Chem. A 104, 4811-4815.

Mao, S.S., Holler, T.P., Yu, G.X., Bollinger, J.M. Jr., Johnston, M.I., and Stubbe, J. (1992a). A model for the role of multiple cysteine residues involved in ribonucleotide reduction: amazing and still confusing. Biochemistry 31, 9733-9743.

Mao, S.S., Holler, T.P., Bollinger, J.M. Jr., Yu, G.X., Johnston, M.I., and Stubbe, J. (1992b). Interaction of C225SR1 mutant subunit of ribonucleotide reductase with R2 and nucleoside diphosphates: tales of a suicidal enzyme. Biochemistry 31 , 9744-9751.

Mao, S.S., Yu, G.X., Chalfoun, D., and Stubbe, J. (1992c). Characterization of C439SR1, a mutant of Escherichia coli ribonucleotide diphosphate reductase: evidence that C439 is a residue essential for nucleotide reduction and C439SR 1 is a protein possessing novel thioredoxin-like activity. Biochemistry 31, 9752-9759.

Mezyk, S.P. and Armstrong, D.A. (1999). Disulfide anion radical equilibria: Effects of $-\mathrm{NH}_{3}{ }^{+},-\mathrm{CO}_{2}{ }^{-},-\mathrm{NHC}(\mathrm{O})-$ and $-\mathrm{CH}_{3}$ groups. J. Chem. Soc. Perkin Trans. 2, 1411-1419.

Mezzetti, A., Maniero, A.L., Brustolon, M., Giacometti, G., and Brunel, L.C. (1999). A tyrosyl radical in an irradiated single crystal of $\mathrm{N}$-acetyl-L-tyrosine studied by X-band cw-EPR, high-frequency EPR, and ENDOR spectroscopies. J. Phys. Chem. A 103, 9636-9643.

Miller, M.A., Gobena, F.T., Kauffmann, K., Munck, E., Que, L., and Stankovich, M.T. (1999). Differing roles for the diiron clusters of ribonucleotide reductase from aerobically grown Escherichia coli in the generation of the Y122 radical. J. Am. Chem. Soc. 121, 1096-1097.

Milov, A.D., Maryasov, A.G., and Tsvetkov, Y.D. (1998). Pulsed electron double resonance (PELDOR) and its application in free-radicals research. Appl. Magn. Reson. 15, 107-143.

Moenne-Loccoz, P., Baldwin, J., Ley, B.A., Loehr, T.M., and Bollinger, J.M. Jr. (1998). $\mathrm{O}_{2}$ activation by non-heme diiron proteins: identification of a symmetric 1,2-peroxide in a mutant of ribonucleotide reductase. Biochemistry 37, 14659-14663.

Mohr, M. and Zipse, H. (1999). C-H bond activation in ribonucleotide reductases - do short strong hydrogen bonds play a role? Chem. Eur. J. 5, 3046-3054.

Nielsen, B.B., Kauppi, B., Thelander, M., Thelander, L., Larsen, I.K., and Eklund, H. (1995). Crystallization and crystallographic investigations of the small subunit of mouse ribonucleotide reductase. FEBS Lett. 373, 310-312.

Nordlund, P. and Eklund, H. (1993). Structure and function of the Escherichia coli ribonucleotide reductase protein R2 J. Mol. Biol. 232, 123-164.

Nordlund, P., Sjöberg, B.-M., and Eklund, H. (1990). Threedimensional structure of the free radical protein of ribonucleotide reductase. Nature 345, 593-598.

Oelgemöller, M., Griesbeck, A.G., Lex, J., Haeuseler, A., Schmittel, M., Niki, M., Hesek, D., and Inoue, Y. (2001). Structural, CV and IR spectroscopic evidences for preorientation in PETactive phthalimido carboxylic acids. Org. Lett. 3, 1593-1596. 
Oelgemöller, M., Haeuseler, A., Schmittel, M., Griesbeck, A.G., Lex, J., and Inoue, Y. (2002). Hydrogen bonding in phthalimido carboxylic acids: cyclic voltammetric study and correlation with photochemical reactivity. Part 2. Aliphatic and aromatic acids. J. Chem. Soc. Perkin Trans. 2, 676-686.

Pelmenschikov, V., Cho, K.-B., and Siegbahn, P.E.M. (2004). Class I ribonucleotide reductase revisited: the effect of removing a proton on Glu441. J. Comp. Chem. 25, 311-321.

Pereira, S., Fernandes, P.A., and Ramos, M.J. (2003). Theoretical study of ribonucleotide reductase mechanism-based inhibition by 2-azido-2-deoxyribonucleoside 5-diphosphates. J. Comp. Chem. 25, 227-237.

Pereira, S., Fernandes, P.A., and Ramos, M.J. (2005). Theoretical study on the inhibition of ribonucleotide reductase by 2 'mercapto-2'-deoxyribonucleoside-5'-diphosphates. J. Am. Chem. Soc. 127, 5174-5179.

Persson, A.L., Eriksson, M., Katterle, B., Pötsch, S., Sahlin, M., and Sjöberg, B.M. (1997). A new mechanism-based radical intermediate in a mutant R1 protein affecting the catalytically essential Glu(441) in Escherichia coli ribonucleotide reductase. J. Biol. Chem. 272, 31533-31541.

Persson, A.L., Sahlin, M., and Sjöberg, B.M. (1998). Cysteinyl and substrate radical formation in active site mutant $\mathrm{E} 441 \mathrm{Q}$ of Escherichia coli class I ribonucleotide reductase. J. Biol. Chem. 273, 31016-312020.

Pötsch, S., Lendzian, F., Ingemarson, R., Hornberg, A., Thelander, L., Lubitz, W., Lassmann, G., and Gräslund, A. (1999). The iron-oxygen reconstitution reaction in protein $\mathrm{R} 2$ tyr-177 mutants of mouse ribonucleotide reductase - EPR and electron nuclear double resonance studies on a new transient tryptophan radical. J. Biol. Chem. 274, 17696-17704.

Ravi, N., Bollinger, J.M., Huynh, B.H., Edmondson, D.E., and Stubbe, J. (1994). Mechanism of assembly of the tyrosyl radical-diiron(III) cofactor of Escherichia coli. 1. Mössbauer characterization of the diferric radical precursor. J. Am. Chem. Soc. 116, 8007-8014.

Reichard, P. (1993). From RNA to DNA, why so many ribonucleotide reductases? Science 260, 1773-1777.

Riggs-Gelasco, P.J., Shu, L., Chen, S., Burdi, D., Huynh, B.H., Que, L. Jr., and Stubbe, J.A. (1998). EXAFS characterization of the intermediate $X$ generated during the assembly of the Escherichia coli ribonucleotide reductase R2 diferric tyrosyl radical cofactor. J. Am. Chem. Soc. 120, 849-860.

Robins, M.J., Wnuk, S.F., Hernandez-Thirring, A.E., and Samano, M.C. (1996). Nucleic acid related compounds. 91. Biomimetic reactions are in harmony with loss of 2 '-substituents as free radicals (not anions) during mechanism-based inactivation of ribonucleotide reductases. Differential interactions of azide, halogen, and alkylthio groups with tributylstannane and triphenylsilane. J. Am. Chem. Soc. 118, 11341-11348.

Robins, M.J., Guo, Z., Samano, M.C., and Wnuk, S.F. (1999). Biomimetic simulation of free radical-initiated cascade reactions postulated to occur at the active site of ribonucleotide reductases. J. Am. Chem. Soc. 121, 1425-1433.

Röck, M. and Schmittel, M. (1993). Controlled oxidation of enolates to $\alpha$-carbonyl radicals and $\alpha$-carbonyl cations. J. Chem. Soc. Chem. Commun. 1993, 1739-1741.

Rova, U., Adrait, A., Pötsch, S., Gräslund, A., and Thelander, L. (1999). Evidence by mutagenesis that Tyr370 of the mouse ribonucleotide reductase $\mathrm{R} 2$ protein is the connecting link in the intersubunit radical transfer pathway. J. Biol. Chem. 274, 23746-23751.

Sahlin, M., Sjöberg, B.-M., Backes, G., Loehr, T., and SandersLoehr, J. (1990). Activation of the iron-containing B2-protein of ribonucleotide reductase by hydrogen-peroxide. Biochem. Biophys. Res. Commun. 167, 813-818.

Salowe, S., Bollinger, J.M. Jr., Ator, M., and Stubbe, J. (1993). Alternative model for mechanism-based inhibition of Escherichia coli ribonucleotide reductase by 2 '-azido-Y-deoxyuridine 5'-diphosphate. Biochemistry 32, 12749-12760.
Schmidt, P.P., Andersson, K.K., Barra, A.L., Thelander, L., and Gräslund, A. (1996). High field EPR studies of mouse ribonucleotide reductase indicate hydrogen bonding of the tyrosyl radical. J. Biol. Chem. 271, 23615-23518.

Schmittel, M. (1994). Umpolung of ketones via enol radical cations. Top. Curr. Chem. 169, 183-230.

Schmittel, M. and Ghorai, M.K. (2001). Reactivity patterns of radical ions - a unifying picture of radical-anion and radicalcation transformations. In: Electron Transfer in Chemistry, Vol. 2, V. Balzani, ed. (Weinheim, Germany: Wiley-VCH), pp. $5-54$.

Scott, C.P., Kashlan, O.B., Lear, J.D., and Cooperman, B.S. (2001). A quantitative model for allosteric control of purine reduction by murine ribonucleotide reductase. Biochemistry 40, 1651-1661.

Siegbahn, P.E.M. (1998). Theoretical study of the substrate mechanism of ribonucleotide reductase. J. Am. Chem. Soc. 120, 8417-8429.

Siegbahn, P.E.M. (1999). Theoretical model studies of the iron dimer complex of MMO and RNR. Inorg. Chem. 38, 2880-2889.

Siegbahn, P.E.M., Eriksson, L., Himo, F., and Pavlov, M. (1998). Hydrogen atom transfer in ribonucleotide reductase (RNR). J. Phys. Chem. B 102, 10622-10629.

Sjöberg, B.-M. (1997). Ribonucleotide reductases - a group of enzymes with different metallosites and a similar reaction mechanism. Struct. Bond. 88, 139-173.

Sjöberg, B.-M., Gräslund, A., and Eckstein, F. (1983). A substrate radical intermediate in the reaction between ribonucleotide reductase from $E$. coli and 2'-azido-2'-deoxynucleoside diphosphates. J. Biol. Chem. 258, 8060-8067.

Sommerhalter, M., Voegtli, W.C., Perlstein, D.L., Ge, J., Stubbe, J., and Rosenzweig, A.C. (2004). Structures of the yeast ribonucleotide reductase Rnr2 and Rnr4 homodimers. Biochemistry $43,7736-7742$.

Steenken, S., Davies, M.J., and Gilbert, B.C. (1986). Pulse-radiolysis and electron spin-resonance studies of the dehydration of radicals from 1,2-diols and related-compounds. J. Chem. Soc. Perkin Trans. 2, 1003-1010.

Strand, K.R., Karlsen, S., Kolberg, M., Rohr, A.K., Görbitz, C.H., and Andersson, K.K. (2004). Crystal structural studies of changes in the native dinuclear iron center of ribonucleotide reductase protein R2 from mouse. J. Biol. Chem. 279, 46794.

Stubbe, J. (1989). Protein radical involvement in biological catalysis? Annu. Rev. Biochem. 58, 257-285.

Stubbe, J. and Ackles, D. (1980). On the mechanism of ribonucleoside diphosphate reductase from Escherichia-coli evidence for $3^{\prime}-\mathrm{C}-\mathrm{H}$ bond-cleavage. J. Biol. Chem. 255, 8027-8030.

Stubbe, J. and van der Donk, W.A. (1998). Protein radicals in enzyme catalysis. Chem. Rev. 98, 705-762.

Stubbe, J., Ator, M., and Krenitsky, T. (1983). Mechanism of ribonucleoside diphosphate reductase from Escherichia-coli evidence for $3^{\prime}-\mathrm{C}-\mathrm{H}$ bond-cleavage. J. Biol. Chem. 258, $1625-1631$.

Stubbe, J., Nocera, D.G., Yee, C.S., and Chang, M.C.Y. (2003). Radical initiation in the class I ribonucleotide reductase: Long-range proton-coupled electron transfer? Chem. Rev. 103, 2167-2201.

Sturgeon, B.E., Burdi, D., Chen, S.X., Huynh, B.H., Edmondson, D.E., Stubbe, J., and Hoffman, B.M. (1996). Reconsideration of $X$, the diiron intermediate formed during cofactor assembly in E. coli ribonucleotide reductase. J. Am. Chem. Soc. 118, 7551-7557.

Thelander, L. (1973). Physicochemical characterization of ribonucleoside diphosphate reductase from $E$. coli. J. Biol. Chem. 248, 4531-4601.

Thelander, L., Larsson, B., Hobbs, J., and Eckstein, F. (1976). Active site of ribonucleoside diphosphate reductase from $E$. coli. Inactivation of the enzyme by 2 -substituted ribonucleoside diphosphates. J. Biol. Chem. 251, 1398-1405. 
Tong, W.H., Chen, S., Lloyd, S.G., Edmondson, D.E., Huynh, B.H., and Stubbe, J. (1996). Mechanism of assembly of the diferric cluster-tyrosyl radical cofactor of Escherichia coli ribonucleotide reductase from the diferrous form of the R2 subunit. J. Am. Chem. Soc. 118, 2107-2108.

Uhlin, U. and Eklund, H. (1994). Structure of ribonucleotide reductase protein $\mathrm{R} 1$. Nature 370, 533-539.

Un, S., Gerez, C., Elleingand, E., and Fontecave, M. (2001). Sen sitivity of tyrosyl radical $g$-values to changes in protein structure: a high-field EPR study of mutants of ribonucleotide reductase. J. Am. Chem. Soc. 123, 3048-3054.

van Dam, P.J., Willems, J.P., Schmidt, P.P., Pötsch, S., Barra, A.L., Hagen, W.R., Hoffman, B.M., Andersson, K.K., and Gräslund, A. (1998). High-frequency EPR and pulsed Q-band ENDOR studies on the origin of the hydrogen bond in tyrosyl radicals of ribonucleotide reductase $\mathrm{R} 2$ proteins from mouse and herpes simplex virus type 1. J. Am. Chem. Soc. 120, 5080-5085.

van der Donk, W.A., Stubbe, J., Gerfen, G.J., Bellew, B.F., and Griffin, R.G. (1995). EPR investigations of the inactivation of E. coli ribonucleotide reductase with 2'-azido-2'-deoxyuridine 5 '-diphosphate: evidence for the involvement of the thiyl radical of C225-R1. J. Am. Chem. Soc. 117, 8908-8916.

van der Donk, W.A., Yu, G., Silva, D.J., Stubbe, J., McCarthy, J.R., Jarvi, E.T., Matthews, D.P., Resvick, R.J., and Wagner, E. (1996). Inactivation of ribonucleotide reductase by (E)-2'-fluoromethylene-2'-deoxycytidine 5 '-diphosphate: a paradigm for nucleotide mechanism-based inhibitors. Biochemistry 35, 8381-8391.

van der Donk, W.A., Gerfen, G.J., and Stubbe, J. (1998). Direct EPR spectroscopic evidence for an allylic radical generated from $(E)-2$ '-fluoromethylene-2'-deoxycytidine $5^{\prime}$-diphosphate by $E$. coli ribonucleotide reductase. J. Am. Chem. Soc. 120, 4252-4253.

Voegtli, W.C., Ge, J., Perlstein, D.L., Stubbe, J., and Rosenzweig, A.C. (2001). Structure of the yeast ribonucleotide reductase Y2Y4 heterodimer. Proc. Natl. Acad. Sci. USA 98, 10073-10078.

Voevodskaya, N., Lendzian, F., and Gräslund, A. (2005). A stable Felll-FelV replacement of tyrosyl radical in a class I ribonucleotide reductase. Biochem. Biophys. Res. Commun. 330, 1213-1216.

Yun, D., Krebs, C., Gupta, G.P., Iwig, D.F., Huynh, B.H., and Bollinger, J.M. Jr. (2002). Facile electron transfer during formation of cluster $\mathrm{X}$ and kinetic competence of $\mathrm{X}$ for tyrosyl radical production in protein $\mathrm{R} 2$ of ribonucleotide reductase from mouse. Biochemistry 41, 981-990.

Zipse, H. (1995). The addition of water to ethylene and transbutene radical-cation - model systems for the reaction of alkene radical cations with nucleophiles. J. Am. Chem. Soc. 117, 11798-11806.

Zipse, H. (2003). The influence of hydrogen bonding interactions on the $\mathrm{C}-\mathrm{H}$ bond activation step in class I ribonucleotide reductases. Org. Biomol. Chem. 1, 692-699. 